Diarte-Blasco, P., Ariño Gil, E., Pérez-Polo, M. (2020): “Asturica (Astorga, León) y Albocela (Villalazán, Zamora) entre la Antigüedad y la Edad Media: análisis comparativo de sus territorios", Spal 29.1: 271-299. DOI: http://dx.doi.org/10.12795/spal.2020.i29.10

\title{
ASTURICA (ASTORGA, LEÓN) Y ALBOCELA (VILLALAZÁN, ZAMORA) ENTRE LA ANTIGÜEDAD Y LA EDAD MEDIA: ANÁLISIS COMPARATIVO DE SUS TERRITORIOS
}

\author{
ASTURICA (ASTORGA, LEÓN) AND ALBOCELA (VILLALAZÁN, ZAMORA) BETWEEN \\ ANTIQUITY AND THE MIDDLE AGES: A COMPARATIVE ANALYSIS OF THEIR TERRITORIES
}

\author{
PILAR DIARTE-BLASCO \\ Responsable de la correspondencia \\ Investigadora Juan de la Cierva-Incorporación. Universidad de Alcalá \\ Correo-e: pilar.diarte@uah.es. D https://orcid.org/0000-0001-7799-593X \\ Researcher ID: <https://publons.com/researcher/R-7288-2018> \\ ENRIQUE ARIÑO GIL \\ Catedrático de Arqueología. Universidad de Salamanca \\ Correo-e: argil@usal.es. D https://orcid.org/0000-0001-8717-2128 \\ Researcher ID: <https://publons.com/researcher/B-6726-2017> \\ MARTA PÉREZ-POLO \\ Investigadora predoctoral. Universidad de Navarra \\ Correo-e: marta.perez.polo@gmail.com. (D https://orcid.org/0000-0002-3359-7726 \\ Researcher ID: <https://publons.com/researcher/AAH-1690-2019>
}

\begin{abstract}
Resumen: Entre el siglo IV y el VI, se observan importantes transformaciones tanto en el espacio urbano como en el rural en la península ibérica. En algunos aspectos, los fenómenos que se detectan tienen su origen en fechas anteriores a la formación de los reinos suevo y visigodo. Otros cambios parecen derivar de procesos puestos en marcha por la creación de nuevos estados en el espacio peninsular. La investigación arqueológica revela importantes transformaciones tanto en el ámbito urbano como en el rural en este periodo. Sin embargo, el espacio urbano y el rural se analizan con frecuencia de forma independiente, sin abordar las diferencias que a veces experimentan en su evolución. En este estudio se aborda el análisis de los cambios en dos ciudades que viven evoluciones urbanas diferentes, Asturica y Albocela, prestando especial atención a la evolución de los espacios de hábitat rural respectivos y confrontándolos con la evolución de los centros urbanos de los que dependen.
\end{abstract}

Palabras clave: Arqueología del Paisaje, Prospección arqueológica, Antigüedad Tardía, Alta Edad Media, Hábitat rural, Valle del Duero.
Abstract: From the fourth century until the sixth, coinciding with the last centuries of the Roman Empire and the consolidation of the Suevic and Visigothic Kingdoms in the Iberian Peninsula, important transformations in both the urban and rural contexts took place. In some cases, the phenomena could probably have their origin in dates before the formation of the Suevi and Visigoth kingdoms, but other changes seem to derive from processes set in motion by the creation of new states in the Iberian Peninsula. Archaeological research reveals important transformations in both urban and rural areas in this period. However, the urban and rural spaces have often been analyzed independently, without addressing the differences they experience in their evolution. In this study we seek to assess changes in both contexts, through close analysis of two cities with different urban evolutions, namely Asturica and Albocela. For each we will evaluate the varied impacts on their respective territories, especially in terms of the types of rural habitat and exploitation.

Keywords: Landscape Archaeology, Archaeological survey, Late Antiquity, Early Medieval Ages, Rural habitat, Duero Valley. 


\section{INTRODUCCIÓN}

Cada vez es más evidente, a juzgar por los datos arqueológicos, que algunas ciudades hispanas que tienen su origen en el principado de Augusto o en la época julio-claudia experimentaron procesos de crisis y abandono en fechas tan tempranas como el siglo II, crisis que parece vinculada a la imposibilidad de mantener a largo plazo el impulso constructivo desarrollado por Augusto y sus sucesores (Martín-Bueno 1999; Andreu Pintado 2017). Este fenómeno matiza en gran medida la crisis urbana de la Antigüedad Tardía, si bien es cierto que el periodo que sigue a la entrada de, primero, suevos, vándalos y alanos, con la posterior llegada de los visigodos, fue acompañado en la península ibérica de la contracción de algunos espacios habitados o, incluso, del colapso urbano de un buen número de ciudades.

La ciudad hispana, en el periodo que incluye el final del imperio romano y los primeros siglos medievales, es un espacio sometido a drásticos cambios. Uno de los fenómenos que la caracterizan es la reconversión de los antiguos edificios públicos (teatros, termas, foros, etc.) hacia nuevos usos, especialmente domésticos o productivos. Al mismo tiempo, el solar urbano experimenta procesos de abandono de algunas zonas, acompañados de expolios y vertidos de basura (Gurt i Esparraguera 2001, Diarte-Blasco 2012, Diarte-Blasco y Gurt i Esparraguera 2015). Sin embargo estos fenómenos no tienen su origen en el siglo V, pues están bien documentados, al menos, ya en el siglo IV. Paralelamente a estos cambios se asiste a la gradual cristianización de la topografía urbana, con la instalación de complejos episcopales, iglesias y monasterios, fenómeno que se produce a partir del siglo $\mathrm{V}$ y que se incrementa, sobre todo, a partir del siglo VI (Gurt i Esparraguera y Sánchez Ramos 2011, Diarte-Blasco 2018: 112-127).

En el contexto rural, lo que se observa es el abandono de la villa como residencia aristocrática, si bien el edificio -o el solar que ocupaba- continúa en uso bajo una amplia diversidad de formas: espacio de hábitat degradado, necrópolis, lugar de culto, área productiva o simple cantera de expolio (Chavarría Arnau 2007). Sin embargo, el final de la villa como lugar de vivienda y representación de las aristocracias bajoimperiales es un fenómeno menos gradual que la mutación que se observa en la ciudad. En Hispania, los fenómenos de cambio en el entorno rural se datan en el marco de la primera mitad del siglo $\mathrm{V}$ y es posible incluso que haya que fecharlos en las dos primeras décadas del siglo $\mathrm{V}$ (aunque respetando las lógicas excepciones tanto antes como después de estas fechas). Desde el mismo momento en que colapsa la villa aristocrática se asiste a la reformulación del espacio agrícola con nuevas formas de hábitat, en un proceso de lenta maduración en el que el siglo VI se revela como un momento de especial relevancia (Ariño Gil 2013).

Pese a que los ritmos del proceso difieren de una zona a otra, la mayor parte de los investigadores que se han ocupado del periodo reconocen evoluciones similares a las que someramente acabamos de detallar. Sin embargo, es probablemente la cuestión relacionada con el abandono total de algunos centros urbanos la que más dudas sigue generando: ¿Por qué ciudades (en principio) similares evolucionan de forma diferente? ¿Por qué unas comienzan una lenta degeneración hasta su olvido, mientras que otras sobreviven o, incluso, mejoran su situación durante estos siglos? ¿Por qué encontramos ambas situaciones a pocos kilómetros de distancia? Son preguntas de difícil respuesta que, sin embargo, provocan un creciente interés entre los investigadores.

En el marco de estas cuestiones presentamos la investigación que llevamos a cabo durante los años 2016 y 2017 en los territorios de Albocela (Villalazán, Zamora) y Asturica (Astorga, León), precisamente por tratarse de dos ciudades con una evolución urbana diferente (fracasando la primera y perviviendo la segunda) y pertenecientes a un mismo paisaje, el del valle medio del Duero, donde la tasa de colapso urbano es considerablemente más alta que en otras zonas peninsulares (Núñez Hernández y Curchin 2007). La investigación, cuyos resultados mostramos aquí, fue diseñada con el propósito de comparar los procesos de evolución de dos ciudades con destinos finales diferentes a partir del examen de sus territorios. Después de todo, en la época romana, el vínculo con el campo fue constante: la riqueza derivada de los territoria de las ciudades fue capital en el desarrollo de estas. Así, más allá del debate de la ciudad vista como consumidor/parásito del campo o de su relación simbiótica o, incluso, de la necesidad de un centro urbano que organiza y redistribuye los excedentes rurales (un análisis de las diferentes posiciones sobre esta relación en Whittaker 1990), de lo que no cabe duda es de que la relación entre el espacio urbano y el territorio que administra es tan intensa que no se puede concebir de forma separada.

En realidad, nada hace pensar que entre el siglo $\mathrm{V}$ y el VI se hubiera producido un cambio en la dinámica entre centro urbano y territorio (Arce 2005: 213-217). La ciudad no se limitaba a sus murallas -por cierto, en muchos casos restauradas en este periodo-, sino que seguía incluyendo su territorium, como se desprende 
de la Chronica de Hidacio. Este autor deja constancia del saqueo de los territoria de Caesar Augusta (en el año 449), Lucus (en el 460) y, precisamente, Asturica (en el año 468), expediciones que, sin alcanzar los centros urbanos, produjeron grandes botines (Hidacio, Chron. 250, 199 y 186; Arce 2005: 216). Del mismo modo, la relación entre ciudad y territorio se hace patente, un siglo más tarde, en la donación y el testamento de Vicente de Asán (de los años 551 y 576 respectivamente). Estos documentos consignan las propiedades de las que Vicente hace entrega al monasterio de Asán situándolas en el marco de los territorios de las ciudades romanas (Ariño Gil y Díaz 2003, Corcoran 2003). La aparición reciente de nuevos documentos relacionados con las donaciones y las gestiones del predio del monasterio de Asán (Tomás-Faci y Martín-Iglesias 2017) han incrementado la nómina de ciudades en las que el cenobio de Asán tenía sus propiedades, confirmando la imagen que se desprendía de la donación y testamento de Vicente. Algunas ciudades, como por ejemplo Labitolosa (La Puebla de Castro, Huesca), están, con toda probabilidad, completamente abandonadas en el periodo en el que se redacta la documentación de Asán (Magallón Botaya y Sillières 2013, Asensio Esteban et al. 2016). Sin embargo, el vínculo ciudad-territorio es tan importante que las propiedades del monasterio se identifican siempre previa alusión al territorio urbano de pertenencia.

Nuestro objetivo en la investigación proyectada en los territorios de Asturica y Albocela era el de comprobar si una evolución urbana diferente tenía también incidencia en el desarrollo de sus respectivos territorios, especialmente en lo referente a los tipos de hábitat rural y a los niveles de pervivencia, discontinuidad y mutación de los mismos. El proyecto fue concebido como un muestreo sobre yacimientos arqueológicos preseleccionados en las dos áreas de actuación. La hipótesis de partida, que el proyecto diseñado aspiraba a comprobar, era que, dado que Albocela, en la secuencia estudiada, es una ciudad en fase de abandono, en tanto que Asturica sobrevive a las crisis del periodo, asumiendo el papel de sede episcopal y convirtiéndose en una de las ciudades más relevantes del reino de León (Cabero Domínguez 1995, Sánchez Badiola 2004), cabía la posibilidad de que esta diferencia repercutiera también en el espacio agrario. El proyecto diseñado contemplaba también valorar en qué medida los recursos del territorio de ambas ciudades podían haber influido en su diferente evolución, teniendo en cuenta que Asturica fue centro, desde época altoimperial, de una importante zona de explotación minera (Domergue 1986: 38-42,
García Marcos y Vidal Encinas 1995: 389-390, Orejas Saco del Valle y Morillo Cerdán 2013).

\section{EL CONTEXTO GEOGRÁFICO E HISTÓRICO}

A inicios del siglo II, en Hispania había más de $300 \mathrm{mu}$ nicipia y alrededor de 30 coloniae (Kulikowski 2005: 34), distribuidos fundamentalmente entre la Bética, las costas y las riberas de los grandes ríos, lugares con una sólida tradición urbana, anterior a la llegada de los romanos. En este sentido, los procesos urbanizadores en la Meseta central y sus estribaciones dieron lugar, en muchos casos, a fundaciones ex nihilo que, en no pocos ejemplos, tras un breve recorrido histórico, fracasaron. Como ya hemos señalado, el área de la Meseta norte es probablemente una de las zonas en las que se observa una mayor incidencia de fracaso urbano desde la secuencia romana hasta la altomedieval (Núñez Hernández y Curchin 2007). Sin embargo algunas ciudades mantienen un rol determinante durante todo este periodo y se configuran como centros determinantes en la topografía urbana medieval. Tal es el caso, por ejemplo, de Asturica. La ciudad nace como campamento romano en el contexto de las Guerras Cántabras (Morillo Cerdán 1991: 163-164), probablemente como base para la Legio X Gemina, pero Augusto la convierte en ciudad y en capital del Conuentus Asturum. Su conversión en asentamiento urbano y la gestión de los metalla publica tuvieron que llevar aparejados cambios sustanciales (Sastre et al. 2017: 542-544). Uno de los más importantes tuvo que ser la constitución de un territorio (Orejas Saco del Valle y Morillo Cerdán 2013: 107-109). Además, los pobladores, entre los cuales se encontrarían probablemente ex legionarios, tuvieron que recibir no solo casa, sino también tierras para su sustento.

No existen argumentos que permitan suponer que Asturica Augusta tuviera un estatuto especial en su momento fundacional (Orejas Saco del Valle y Morillo Cerdán 2013: 93-94, Sastre et al. 2017: 543). Sin embargo, es cierto que Asturica presenta unos rasgos especiales que le dan un carácter singular si se la compara con otras ciudades peregrinas. En primer lugar su sobrenombre de Augusta, que avala una intervención imperial directa en su constitución. En segundo lugar su planta urbana, regular y con dos tramas ortogonales imbricadas, creadas ex novo y con un foro destinado al culto imperial (Le Roux 2009, Sevillano Fuertes 2013, Vidal Encinas y González Fernández 2018). En tercer lugar su función como capital de conuentus, papel para el que siempre se 
eligen colonias o ciudades de rango privilegiado, aunque existan excepciones conocidas como Bracara $\mathrm{Au}$ gusta y Lucus Augusti, las cuales además presentan muchos paralelismos con Asturica. En cuarto lugar el hecho de que en su fundación intervengan militares o individuos de origen militar (Mañanes Pérez 1982: 21-52, Vidal Encinas y González Fernández 2004, v. también Rabanal Alonso y García Martínez 2001). Por último, el término urbs magnifica que utiliza Plinio (Nat. 3.28), nos indica que Asturica no era un asentamiento cualquiera, sino una ciudad que respondía a los modelos de organización más puramente romanos. Independientemente de cuál fuera su estatuto jurídico, el hecho es que se trataba de una auténtica ciudad para el naturalista latino, equiparable, al menos en sus aspectos formales, a otras de las consideradas como de rango privilegiado.

Entre el reinado de Tiberio y el de Claudio, coincidiendo con la construcción de los primeros edificios de carácter civil -como el foro, que ocupó un espacio de 3 ha y era de planta cuadrangular, con tres de sus lados porticados (Sevillano Fuertes 2013: 118)-, se erigió la muralla altoimperial de la ciudad (con una anchura de 2,5 m), de la que, a día de hoy, se conocen pocos tramos (Vidal Encinas y González Fernández 2018: 277 y 280-281). No sabemos si coincidiría con la bien conocida muralla tardoantigua, construida entre finales del siglo III o inicios del siglo IV y que, con una longitud de unos $2,2 \mathrm{~km}$, encerraba un recinto de c 26 ha de superficie. Similar a las murallas de León o Lugo, esta construcción llegó a duplicar el espesor del amurallamiento original, entre 4 y $5 \mathrm{~m}$, destacando además la altura de las torres que lo jalonaban (Sevillano Fuertes 2007, Vidal Encinas y González Fernández 2018: 277 y 280-281).

El auge constructivo de la ciudad, no obstante, tuvo lugar en el periodo flavio (García Marcos y Vidal Encinas 1996: 135, Orejas Saco del Valle y Morillo Cerdán 2013: 96-97), siendo en este momento cuando la ciudad se dota de complejos termales (destacando las Termas Mayores y las Menores: Sevillano Fuertes y Vidal Encinas 2000, García Marcos y Burón 2000, Vidal Encinas y González Fernández 2018: 282-284). Sin embargo, esta explosión constructiva no durará demasiado, ya que en el siglo III, probablemente en relación con el decaimiento de la actividad minera en la región, la ciudad experimentará un cierto estancamiento (Orejas Saco del Valle y Morillo Cerdán 2013: 98).

En el siglo IV, Asturica se convertirá en sede episcopal, información que conocemos a través de una carta del obispo de Cartago, Cipriano (Epístola LXVII, Teja Caruso 1990: 117). Pese a ello, los restos constructivos pertenecientes a los siglos IV y V son muy escasos, algo que contrasta con la gran cantidad de material cerámico de la misma época hallado en la ciudad, el cual está compuesto sobre todo por recipientes de origen peninsular, aunque no faltan producciones procedentes de territorios galos y africanos (Morillo Cerdán y Amaré Tafalla 2003, Paz Peralta 2013). El abundante material cerámico recuperado estaría señalando un dinamismo comercial de la ciudad como principal núcleo de redistribución y consumo de la zona hasta, por lo menos, mediados del siglo $\mathrm{V}$ d.C.

La falta de documentación sobre las estructuras arquitectónicas bajoimperiales se prolonga en el periodo suevo/visigodo, en contraste con la información proporcionada por las fuentes escritas, relativamente abundante (Fernández Ochoa et al. 2005: 100-102). No obstante, cabe destacar el hallazgo de un modesto edificio cristiano, datado entre finales del siglo VI y el siglo VII, en la zona de la actual iglesia de santa Marta, junto a la catedral medieval (Sevillano Fuertes y Vidal Encinas 2002). El edificio, que aprovecha como cimentación el hypocaustum de unas termas romanas, es de nave única y conservaba in situ el pavimento de opus signinum y el pie de una mensa, siendo posible identificar en él el sanctuarium, el coro y el espacio que ocuparía la congregación. Dentro de la nave, además, se pudo documentar una estructura que se ha identificado como un posible baptisterio (Martín López y Sevillano Fuertes e.p.).

Es necesario señalar que la organización del entorno de la ciudad responde, desde el inicio, a la cercanía a los principales yacimientos auríferos del territorio astur, siendo quizá por ese motivo la cabeza visible de la administración regional hasta que, tras la reorganización dioclecianea -en la que los conventus Bracarense, Lucense y Asturicense se desgajan de la antigua provincia Tarraconense y se integran en la nueva provincia Gallaecia-, la capitalidad fue asumida por Bracara Augusta. Se ha sugerido, de hecho, que este traslado podría haber estado relacionado, además de con otros factores, con el abandono en el primer tercio del siglo III de la explotación estatal del oro en la zona de Asturica y su desplazamiento hacia el sector galaico (Sánchez-Palencia 1995: 148, Morillo Cerdán y Amaré Tafalla 2003: 122-123). En cualquier caso, no cabe duda de que la implantación del control romano en el territorio de Asturica estuvo desde el inicio íntimamente relacionada con la actividad económica apenas referida, que creó una nueva organización del territorio. El castro pre-romano autosuficiente dejó de ser la unidad territorial fundamental (aunque algunos de ellos subsistieron y otros nuevos se crearon, sobre todo 
donde la morfología del terreno no permitía otro tipo de asentamiento). Es probable, además, que la utilización de los castros pudiese ser intermitente, respondiendo a las necesidades de la explotación aurífera, y con una alta movilidad de los trabajadores que, a partir de labores de prospección en las que desde las zonas bajas se remontaban los valles, buscaban las zonas con mayor potencial mineral para establecer la explotación (Sánchez-Palencia et al. 2000). Por otro lado, más allá de los espacios castreños, surgieron también nuevos asentamientos, de diferente forma y configuración, que solo tuvieron sentido como parte de una red de poblamiento y explotación minera regional, así como villas, mucho más conectadas con el poblamiento tradicional romano que, con un evidente carácter aristocrático, fueron claves en la jerarquización del territorio.

El caso de Albocela es bastante diferente del de Asturica (las ciudades distan c $115 \mathrm{~km}$ ), tanto en el desarrollo urbano, como en la organización de su paisaje, mucho más similar a la forma tradicional de ocupación rural romana. Albocela es un núcleo urbano ubicado a orillas del Duero, a medio camino entre Zamora y Toro, al oeste de la actual población de Villalazán y dentro de su término municipal. El asentamiento mide unos $1.000 \mathrm{~m}$ en sentido E-W por $500 \mathrm{~m}$ en sentido N-S. Las dimensiones totales del espacio urbano rondan las 50 ha, lo que supone una ciudad de tamaño medio para la península ibérica. La ciudad romana nace sobre el precedente de un establecimiento de la Edad del Hierro identificado en los trabajos de prospección en la zona conocida como Valcuevo. Al occidente del espacio urbano, que es de trama regular, la prospección aérea reveló trazas de un campamento romano. A juzgar por el hallazgo de terra sigillata itálica y gálica en el muestreo superficial, la trama urbana regular podría datar del principado de Augusto o Tiberio (Ariño Gil et al. 2007). Apenas se han practicado excavaciones en la ciudad, si bien en 1987 se intervino en un edificio que fue interpretado como unas termas (González Serrano 1990, Martín Arija et al. 1994a y 1994b, García Rozas 1995). Los trabajos de prospección en Albocela indican que el espacio urbano está ocupado (no sabemos en qué forma) al menos hasta el siglo $\mathrm{V}$, momento a partir del cual se asistiría al abandono de la ocupación (Ariño Gil et al. 2007: 192).

\section{BASES CIENTÍFICAS Y DISEÑO DEL PROYECTO}

La investigación que hemos llevado a cabo partía de una división del espacio de trabajo en dos zonas diferentes, cada una de ellas jerarquizada en torno a las ciudades romanas de Albocela y Asturica. Su objetivo era llevar a cabo un muestreo superficial en distintos tipos de asentamientos en el territorio de cada uno de los dos centros urbanos elegidos como modelos. Los asentamientos del periodo comprendido entre el c 400 y c 800 presentan una gran diversidad morfológica, por lo que la preselección de puntos de muestreo aspiraba a incluir al menos las categorías que se consideran más significativas del periodo: 1) el castro prerromano con ocupación tardía, así como otros poblados en altura; 2) la villa romana con evidencias de ocupación posteriores al año 400; 3) otros asentamientos romanos en llano, en el caso de Asturica, especialmente, puntos de hábitat asociados a la explotación minera; 4) asentamientos suevo/visigodos o altomedievales en llano; 5) necrópolis tardías, con posibles puntos de hábitat asociado; 6) despoblados o aldeas plenomedievales que pudieran albergar una secuencia de ocupación de periodos anteriores.

La selección de yacimientos para el muestreo se enfrenta, desde su principio, al problema de que los territorios urbanos objeto de estudio no tienen límites geográficos precisos, siendo posible solamente una definición aproximada de los mismos partiendo de su relación con las ciudades vecinas. Por ello, se seleccionaron para la base de datos inicial aquellos yacimientos que quedaran incluidos en un polígono que tuviera a cada una de las ciudades en su punto central y que, por su proximidad al centro urbano, pudieran considerarse con cierta seguridad como dependientes de este. Si bien se trata de una solución pragmática, puede considerarse que todos los yacimientos sobre los que se ha actuado estarían efectivamente dentro de los territorios urbanos analizados.

La base de datos utilizada como documentación de partida fue el Inventario Arqueológico de Castilla y León (IACyL), complementado o refrendado con la literatura científica disponible sobre cada uno de los yacimientos. Con frecuencia, la adscripción cultural de un yacimiento en el IACyL es poco fiable (Ariño Gil y de Soto García 2016). Este problema deriva de varios factores, entre los que cabe destacar especialmente que la clasificación cultural del yacimiento - a partir del material de prospección- es en gran medida intuitiva y se basa sobre todo en criterios cualitativos, basados en ocasiones en la identificación de unos pocos fragmentos cerámicos en superficie (en menor medida, también de otros materiales arqueológicos, como epigrafía, monedas u otros hallazgos). En el caso del territorio asturicense, el problema de la clasificación cultural del yacimiento 


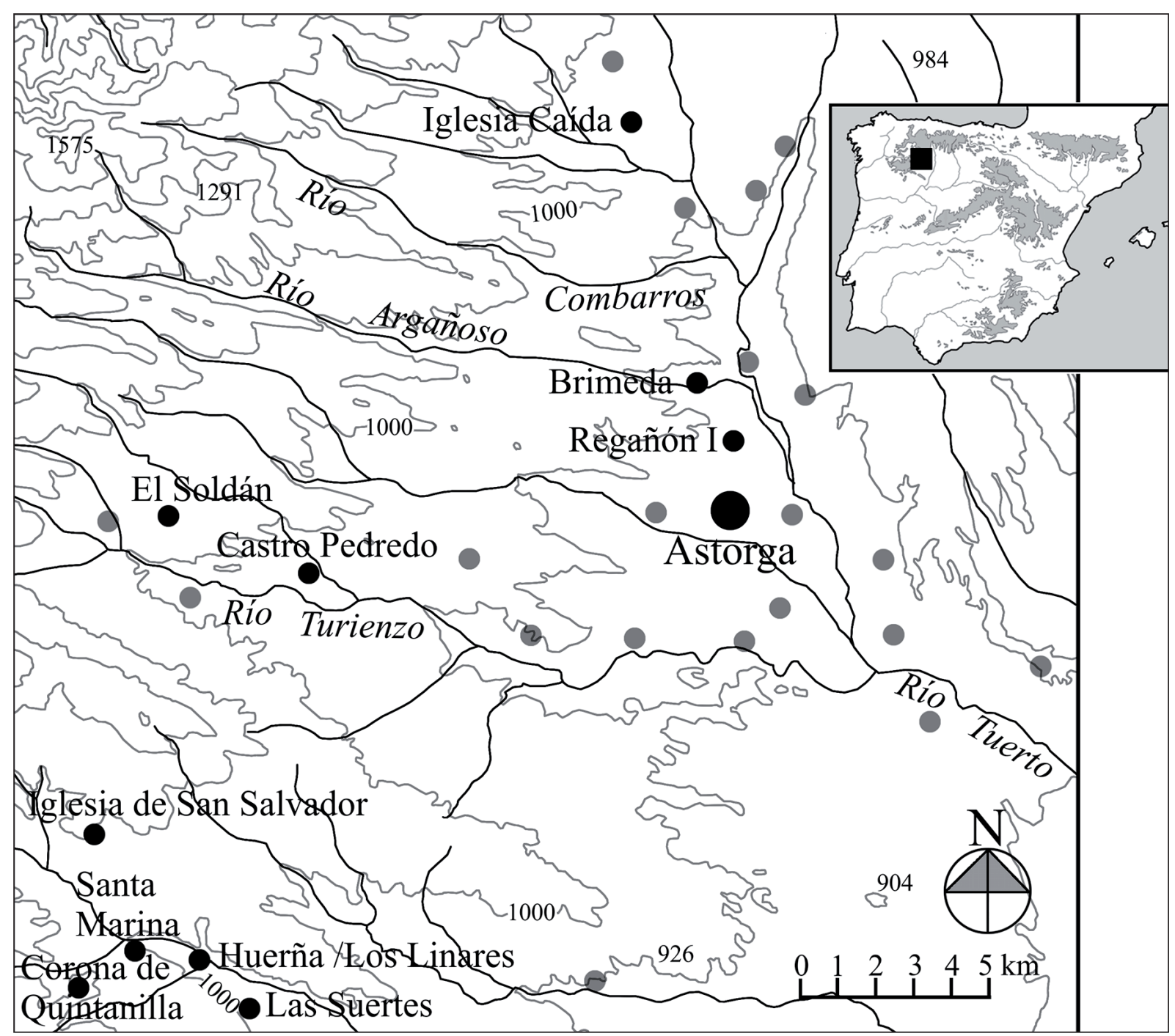

Figura 1. Mapa del territorio de Asturica, en el que se señalan los yacimientos que poseen indicadores en superficie de ocupación en época romana o de la secuencia tardoantigua (se valora la presencia de tegula, terra sigillata, itálica, gálica, hispánica o hispánica tardía, cerámica común de cocina o cerámica común de cocina decorada con líneas bruñidas). Se destacan los yacimientos prospectados. Imagen elaborada sobre base cartográfica de Iberpix 4, Instituto Geográfico Nacional.

se complica por el hecho de que muchos asentamientos del periodo romano se definen por la morfología de su planta a partir del análisis de la fotografía aérea o de satélite (por la presencia de fosos de circunvalación) y por sus localizaciones características junto a explotaciones mineras, sin que el examen superficial (por circunstancias asociadas a una muy deficiente visibilidad) permitan recuperar material cerámico (Orejas Saco del Valle 1996). Por ello, la preselección de puntos de visita se hizo privilegiando aquellos yacimientos en los que el IACyL y la literatura científica informaban de la observación de material cerámico en superficie.
En el territorio de Asturica se preseleccionaron para el estudio 30 yacimientos (fig. 1) que se juzgaron como susceptibles de aportar información positiva en un muestreo superficial. Trece de ellos fueron objeto de prospección (por estimarse que eran los que mejor definían las categorías objeto de análisis), pero solo cinco revelaron material cerámico en superficie y pudieron ser objeto de muestreo (tab. 1). Estos cinco yacimientos se juzgaron representativos de distintos modelos de hábitat con secuencias de los periodos de interés. Castro Pedredo (Santa Colomba de Somoza) estaba catalogado como un castro prerromano y romano asociado a 
Tabla 1. Yacimientos prospectados en el territorio de Asturica. Se señala el topónimo, municipio, material registrado en los informes del IACyL y resultado de la prospección.

\begin{tabular}{|l|l|l|l|}
\hline \multicolumn{1}{|c|}{ Yacimiento } & \multicolumn{1}{|c|}{ Municipio } & \multicolumn{1}{c|}{ Indicadores } & \multicolumn{1}{c|}{ Prospección } \\
\hline Santa Marina & Luyego & tegula & negativa \\
\hline Huerña/Los Linares & Luyego & excavado: asentamiento romano altoimperial & $\begin{array}{l}\text { superficie muestreada: } \\
8.330 \mathrm{~m}^{2}\end{array}$ \\
\hline Las Suertes & Luyego & $\begin{array}{l}\text { terra sigillata hispánica, cerámica de paredes } \\
\text { finas, tegula }\end{array}$ & negativa \\
\hline Corona de Quintanilla & Luyego & excavado: asentamiento romano altoimperial & negativa \\
\hline Iglesia de San Salvador & Luyego & tegula & negativa \\
\hline Iglesia Caída & Magaz de Cepeda & terra sigillata hispánica & $\begin{array}{l}\text { superficie muestreada: } \\
8.131 \mathrm{~m}^{2}\end{array}$ \\
\hline Castro Pedredo & Santa Colomba de Somoza & terra sigillata hispánica, tegula & $\begin{array}{l}\text { superficie muestreada: } \\
14.139 \mathrm{~m}^{2}\end{array}$ \\
\hline El Soldán & Santa Colomba de Somoza & excavado: villa romana altoimperial & negativa \\
\hline Regañón I & Villaobispo de Otero & terra sigillata hispánica & $\begin{array}{l}\text { superficie muestreada: } \\
37.357 \mathrm{~m}^{2}\end{array}$ \\
\hline Brimeda & Villaobispo de Otero & Sin datos & $\begin{array}{l}\text { superficie muestreada: } \\
386.854 \mathrm{~m}^{2}\end{array}$ \\
\hline
\end{tabular}

los frentes de explotación de minería antigua conocida como Los Fuellos (Orejas Saco del Valle 1996: 74-78, 117 y 194). Huerña/Los Linares (Luyego) se identificaba como un hábitat minero no castreño con secuencia de ocupación altoimperial, asociado a las explotaciones de Los Castellones-Río Llamas (Orejas Saco del Valle 1996: 154 y 192). En este yacimiento se habían practicado excavaciones que habían puesto al descubierto estructuras de vivienda datadas en los siglos I-II (Domergue y Martin 1977). Iglesia Caída (Magaz de Cepeda) presentaba una morfología que permitía proponerlo como un castro con secuencia de habitación en el periodo romano y altomedieval. Como materiales significativos de la secuencia más antigua en este asentamiento se registraban dos fíbulas zoomorfas y una figura de un gallo, todas en bronce, que en la actualidad se hallan en el Museo de León ( $\mathrm{n}^{\circ}$ de inventario 398, 399 y 671), si bien, en el desarrollo del trabajo de campo, la atribución de estos materiales al yacimiento de Iglesia Caída resultó ser dudosa ${ }^{1}$. Regañón I (Villaobispo de Otero) se definía como hábitat rural en llano con secuencias del periodo romano altoimperial y

1. Información personal de Luis Grau Lobo, Museo de León, 26 de enero de 2017. tardío. El quinto espacio de prospección se situó en el entorno de Brimeda (Villaobispo de Otero). Brimeda no es propiamente un yacimiento, ya que es una aldea fundada en el siglo IX que continúa habitada en la actualidad. Un importante documento datado en el año 878 atestigua labores de colonización agrícola basadas en la construcción de un parcelario regular asociado a la fundación de la aldea, denominada como Villa Vimineta (Floriano Cumbreño 1951: 127-130 -doc. 120, Ariño Gil et al. 2004: 203-209). Brimeda era un caso de especial interés para los objetivos de nuestro estudio, ya que debía permitir abordar la cuestión de si se trataba de una fundación ex novo -como al parecer permite suponer el documento que, además, de forma expresa menciona la organización de su parcelario, la puesta en cultivo y su edificación (...et fecit ibidem suas signas et aedificauit ibidem casas, cortes, arauit, seminauit in ipsa uilla...)- o si la aldea se estableció sobre el precedente de una ocupación anterior.

Por último, pese a que no pudo ser objeto de muestreo superficial a causa de la mala visibilidad que el yacimiento presenta en la actualidad, se ha incluido en el estudio el yacimiento de El Soldán (Santa Colomba de Somoza). El Soldán es sin duda la villa romana mejor documentada del territorio de Asturica. (Mañanes 


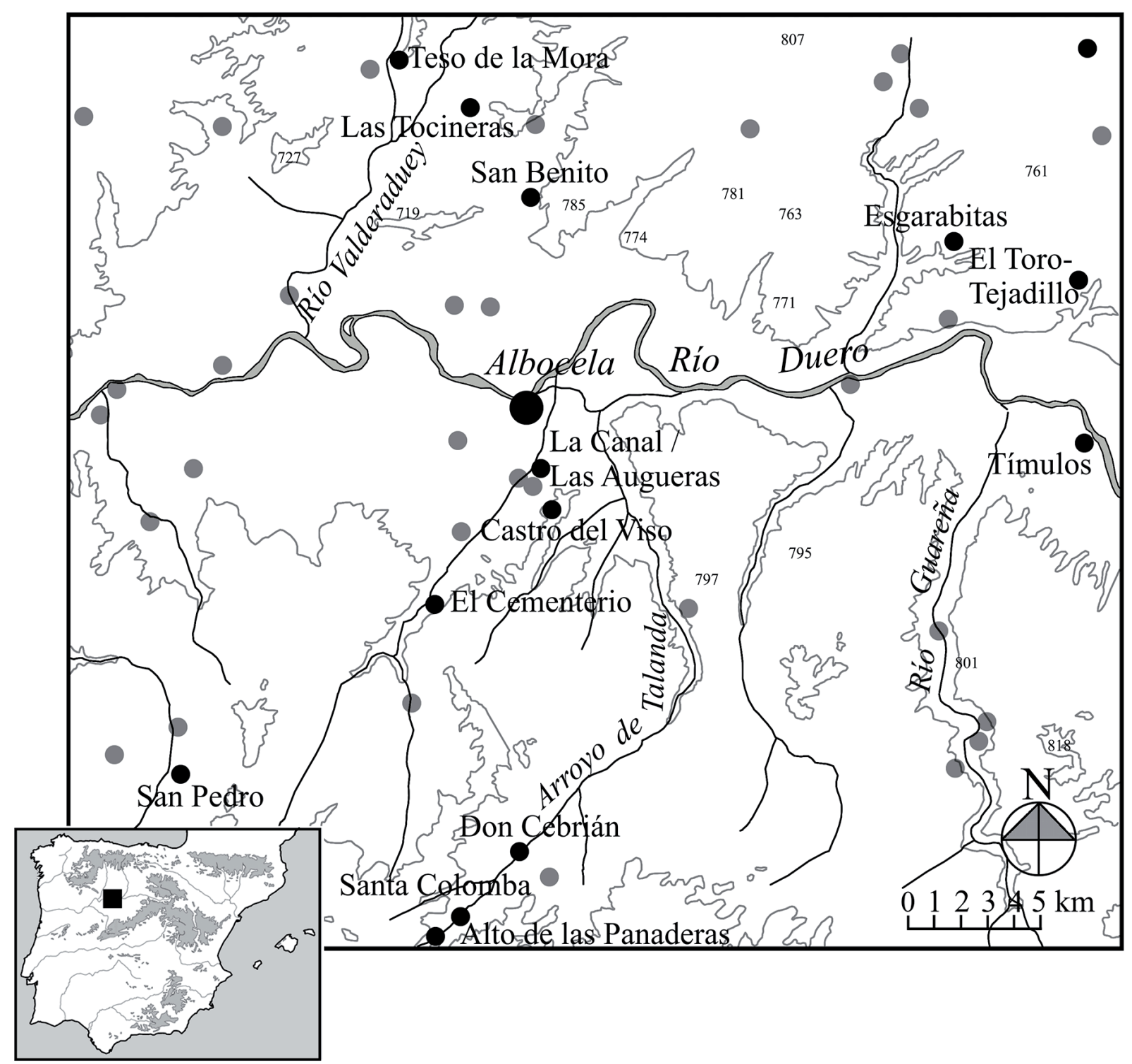

Figura 2. Mapa del territorio de Albocela, en el que se señalan los yacimientos que poseen indicadores en superficie de ocupación en época romana o de la secuencia tardoantigua (se valora la presencia de tegula, terra sigillata, itálica, gálica, hispánica o hispánica tardía, cerámica común de cocina o cerámica común de cocina decorada con líneas bruñidas). Se destacan los yacimientos prospectados. Imagen elaborada sobre base cartográfica de Iberpix 4, Instituto Geográfico Nacional.

Pérez 1977, Gorges 1979: 276-277, García-Entero 2001: 141-147). Ante la imposibilidad de obtener un contexto superficial, el análisis de los contextos cerámicos de la villa de El Soldán se llevó a cabo sobre el material cerámico recuperado en las excavaciones llevadas a cabo por Carro en los inicios del siglo XX (Carro 1934). Este material está depositado en el Instituto Leonés de Cultura y fue tratado como conjunto, ya que no existe constancia de su registro estratigráfico. Sin embargo, puede juzgarse representativo de la secuencia de ocupación del asentamiento, ya que su examen reveló que no había sido objeto de selección por parte de su excavador. Así, los contextos de excavación incluyeron, junto a piezas de cerámica de mesa, numerosos fragmentos de cerámicas comunes y de cocina.

En el territorio de Albocela se preseleccionaron 47 yacimientos en total (fig. 2). De ellos, 13 fueron objeto de prospección superficial con el fin de valorar 
Tabla 2. Yacimientos prospectados en el territorio de Albocela. Se señala el topónimo, municipio, material registrado en los informes del IACyL y resultado de la prospección.

\begin{tabular}{|c|c|c|c|}
\hline Yacimiento & Municipio & Indicadores & Prospección \\
\hline San Benito & Algodre & terra sigillata hispánica, tegula & negativa \\
\hline San Pedro & Casaseca del Campeán & $\begin{array}{l}\text { terra sigillata hispánica, cerámica común de } \\
\text { cocina }\end{array}$ & negativa \\
\hline Alto de las Panaderas & Cuelgamures & terra sigillata hispánica, tegula & negativa \\
\hline Santa Colomba & Fuentespreadas & excavado: necrópolis romana tardía & negativa \\
\hline Don Cebrián & Fuentespreadas & $\begin{array}{l}\text { cerámica estampillada, cerámica común de } \\
\text { cocina, tegula }\end{array}$ & negativa \\
\hline El Cementerio & Gema & $\begin{array}{l}\text { terra sigillata hispánica, terra sigillata } \\
\text { hispánica tardía, cerámica pintada, cerámica de } \\
\text { paredes finas, lucerna, tegula }\end{array}$ & $\begin{array}{l}\text { superficie muestreada: } \\
2.368 \mathrm{~m}^{2}\end{array}$ \\
\hline Castro del Viso & Madridanos & cerámica pintada celtibérica & $\begin{array}{l}\text { superficie muestreada: } \\
3.212 \mathrm{~m}^{2}\end{array}$ \\
\hline La Canal/Las Augueras & Madridanos & $\begin{array}{l}\text { terra sigillata hispánica, terra sigillata } \\
\text { hispánica tardía cerámica pintada, tegula }\end{array}$ & negativa \\
\hline Teso la Mora & Molacillos & excavado: cisternas romanas & $\begin{array}{l}\text { superficie muestreada: } \\
1.107 \mathrm{~m}^{2}\end{array}$ \\
\hline Las Tocineras & Molacillos & terra sigillata hispánica, tegula & negativa \\
\hline El Toro-Tejadillo & Toro & $\begin{array}{l}\text { cerámica pintada celtibérica, terra sigillata } \\
\text { hispánica, tegula }\end{array}$ & $\begin{array}{l}\text { superficie muestreada: } \\
4.047 \mathrm{~m}^{2}\end{array}$ \\
\hline Esgarabitas & Toro & cerámica común de cocina & negativa \\
\hline Tímulos & Toro & cerámica común de cocina & $\begin{array}{l}\text { superficie muestreada: } \\
4.445 \mathrm{~m}^{2}\end{array}$ \\
\hline
\end{tabular}

su idoneidad para llevar a cabo un muestreo (tab. 2), pero solo en cinco se pudo recuperar un contexto cerámico superficial significativo. El Castro del Viso (Madridanos) estaba definido como un importante castro de la II Edad del Hierro (Martín Valls 1973: 403405, 1995: 154-157 y 172), pero con posibles indicios de ocupación en el periodo medieval (Larrén Izquierdo 1994: 336). A la misma categoría de castro prerromano, pero con una ocupación romana al parecer significativa, correspondía el Teso de la Mora (Molacillos), donde se habían excavado dos importantes cisternas romanas de opus signinum en cuyos niveles de amortización se había recuperado terra sigillata itálica, la cual fechaba el final de uso de las cisternas hacia los últimos años del reinado de Augusto o en los primeros años del de Tiberio (Martín Valls y Delibes de Castro 1976: 427-429, Balado Pachón y Martínez García 2008). El Cementerio (Gema) (Martín Valls 1973: 405, Pérez
Centeno 1990: 447) y El Toro-Tejadillo (Toro) (Martín Valls y Delibes de Castro 1977: 309-311) estaban definidos por la investigación previa como villas romanas, con indicios de ocupación tardía. En el Cementerio se había practicado una excavación de urgencia, aunque con escasos resultados (Larrén Izquierdo 1994: 338-339). Por último, el yacimiento de Tímulos (Toro) podía catalogarse, a juzgar por el material obtenido en las investigaciones previas anotadas en el IACyL, como un asentamiento en llano del periodo suevo/visigodo y altomedieval. En este caso existía además el interés adicional de que el topónimo Tímulos estaba registrado como lugar poblado en el año 1208 (Pascual Sánchez 1991: 198-199).

Resulta de interés destacar los resultados negativos del muestreo en la necrópolis de Santa Colomba (Fuentespreadas). Santa Colomba (Caballero Zoreda 1974) es uno de los yacimientos más representativos de lo que en 
su día fue caracterizado como "necrópolis del Duero" (Palol 1958) y que hoy se prefiere considerar como necrópolis tardorromanas o post-imperiales (Fuentes Domínguez 1989, Vigil-Escalera 2015: 71-78 y 155-162). La prospección no proporcionó material cerámico en superficie en la zona en la que se localiza el yacimiento ni en el Alto de las Panaderas, un sitio en el que el IACyL localizaba restos compatibles con la cronología de las necrópolis, lo cual deja abierta la contextualización y lectura de las inhumaciones documentadas. En el yacimiento de San Pedro (Casaseca del Campeán), considerado por el IACyL como despoblado medieval, se desestimó el muestreo porque la prospección superficial previa no ofreció fragmentos cerámicos a la vista, aunque sí un abundante número de fragmentos de teja.

\section{MÉTODOS Y TÉCNICAS}

Como paso previo al muestreo se realizó, en todos los yacimientos preseleccionados (trece para cada uno de los territorios), una inspección previa. Esta inspección previa no incluyó la recogida de material arqueológico. Su finalidad era, por un lado, chequear la información contenida en el IACyL y comprobar la presencia de restos cerámicos en superficie en el área marcada en los registros cartográficos del IACyL y, por otro, seleccionar el espacio de intervención en el yacimiento, atendiendo especialmente a las condiciones de visibilidad superficial en el momento de la actuación. Los datos obtenidos en esta inspección ocular previa, como hemos señalado antes, obligaron a modificar el plan de trabajo original ya que solo una parte de los yacimientos preseleccionados (un 41,6\% del conjunto del entorno de Albocela y un $30,7 \%$ en el de Asturica) exhibía restos cerámicos en esta inspección superficial. No siempre fue posible determinar la causa de esta discordancia entre los datos del IACyL y los obtenidos en nuestra visita, la cual en algunos casos pudiera deberse a problemas de visibilidad superficial en el momento de la inspección, pero también a deficiencias de actuación en los registros previos, deficiencias derivadas de dos posibles fenómenos: a) sobrevaloración de material off-site como indicativo de la existencia de un yacimiento y; b) error en la localización geográfica del yacimiento, a causa de un registro cartográfico incorrecto, derivado en ocasiones de la coincidencia de topónimos en dos áreas distintas o debido a otras causas y factores imposibles de determinar. Por otro lado, incluso en varios de aquellos sitios en los que la inspección previa revelaba la presencia de material cerámico en superficie, las condiciones de visibilidad no eran las óptimas para, como inicialmente habíamos previsto, realizar un muestreo mediante cuadrículas de $10 \mathrm{~m}$ de lado (sistema ensayado satisfactoriamente en la provincia de Salamanca y que se había revelado como eficaz para definir las secuencias de ocupación de los yacimientos basada en la cuantificación del material cerámico, vid. Ariño et al. 2015, Ariño Gil y Soto García 2016), ya que solo pequeños espacios discontinuos presentaban las condiciones de visibilidad adecuadas. En este sentido, se concluyó que la solución óptima para las características de los territorios en estudio era la de una estrategia de muestreo basada en la recolección integra de todo el material observado en superficie en la zona marcada, siendo cada pieza o fragmento registrada como way-point en coordenadas GPS.

Como ya se ha expuesto, la clasificación cultural que registra el IACyL se basa en la observación del material cerámico superficial atendiendo a valores cualitativos. Sin embargo, como ya hemos argumentado en otras ocasiones (Ariño Gil y Rodríguez Hernández 1997, Ariño Gil et al. 2002), la secuencia altomedieval es subestimada en este tipo de examen, ya que el material de este periodo (que incluye la secuencia suevo/visigoda) se caracteriza por la asociación tegula/cerámica común de cocina, siendo el material característico del periodo (cerámica estampillada o TSHip, cerámica común de cocina decorada con líneas bruñidas) muy escaso (Ariño Gil y Dahí Elena 2012, Dahí Elena 2012). En el registro estratificado, la cerámica de cocina es el material más abundante, a partir de mediados o finales del siglo $\mathrm{V}$ y hasta una época no bien determinada, que en nuestra zona de trabajo al menos alcanza los inicios del siglo IX (Ariño Gil y Dahí Elena 2012, Dahí Elena 2012, Vigil-Escalera 2013, Sastre Blanco et. al. 2018: 392-396). En el registro superficial no es fácil poder reconstruir tipologías (por otro lado no determinantes para elaborar cronologías, ya que el repertorio formal de esta producción es muy sencillo). Sin embargo altos valores del número de fragmentos de cerámica común de cocina, asociados a la presencia minoritaria de terra sigillata hispánica tardía o de cerámica de cocina decorada con líneas bruñidas, se juzgan indicadores suficientes para proponer una ocupación en el periodo tardoantiguo o altomedieval.

El registro del material en coordenadas GPS favorece la cuantificación, permite abordar un análisis del yacimiento en el nivel del microespacio, facilitando la detección de variaciones en la intensidad de ocupación zonal, y sirve para definir los límites exactos de la superficie muestreada al registrar el recorrido de cada uno de los prospectores mediante tracks. Los datos fueron registrados sobre la base cartográfica del Instituto Geográfico 


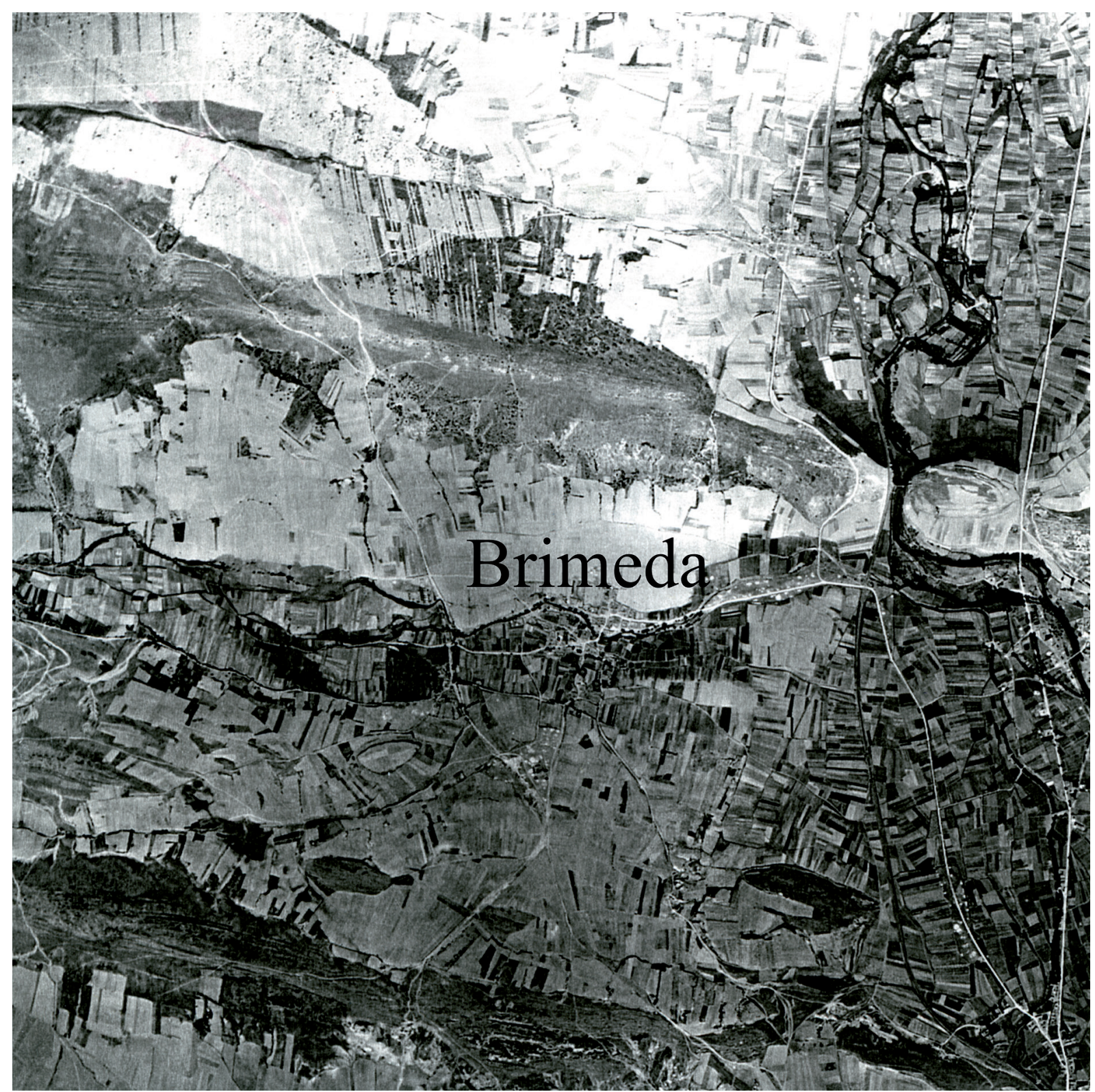

Figura 3. Fotografía aérea del año 1956 en que se aprecia el parcelario regular en torno a Brimeda (Servicio Geográfico del Ejército, fot. 14931-R. 160-27 de julio de 1956). Escala original del vuelo 1: 33.000 aprox.

Nacional (portal $<$ http://pnoa.ign.es/productos $>$ ) en una herramienta SIG (sistema de código libre QGIS, 2.18 Las Palmas: <https://qgis.org/es/site/about/index.html>.).

El estudio de Brimeda, villa fundada en el año 878, parte de la interpretación del fotograma aéreo del Servicio Geográfico del Ejército (fot. 14931, R. 160, 27 de junio de 1956), el cual permite apreciar un parcelario regular jerarquizado en tono a la aldea que es con toda probabilidad aquel al que hace referencia el documento (fig. 3). Partiendo de esta información, se diseñó un muestreo del entorno agrícola de Brimeda con el fin de recuperar material cerámico off-site en las tierras de cultivo, partiendo de la hipótesis de que las labores de abonado realizadas con basura doméstica podrían albergar un registro de toda la secuencia de actuación humana sobre un paisaje histórico y, de ser así, el registro cerámico podría incluir materiales de la secuencia altomedieval. 


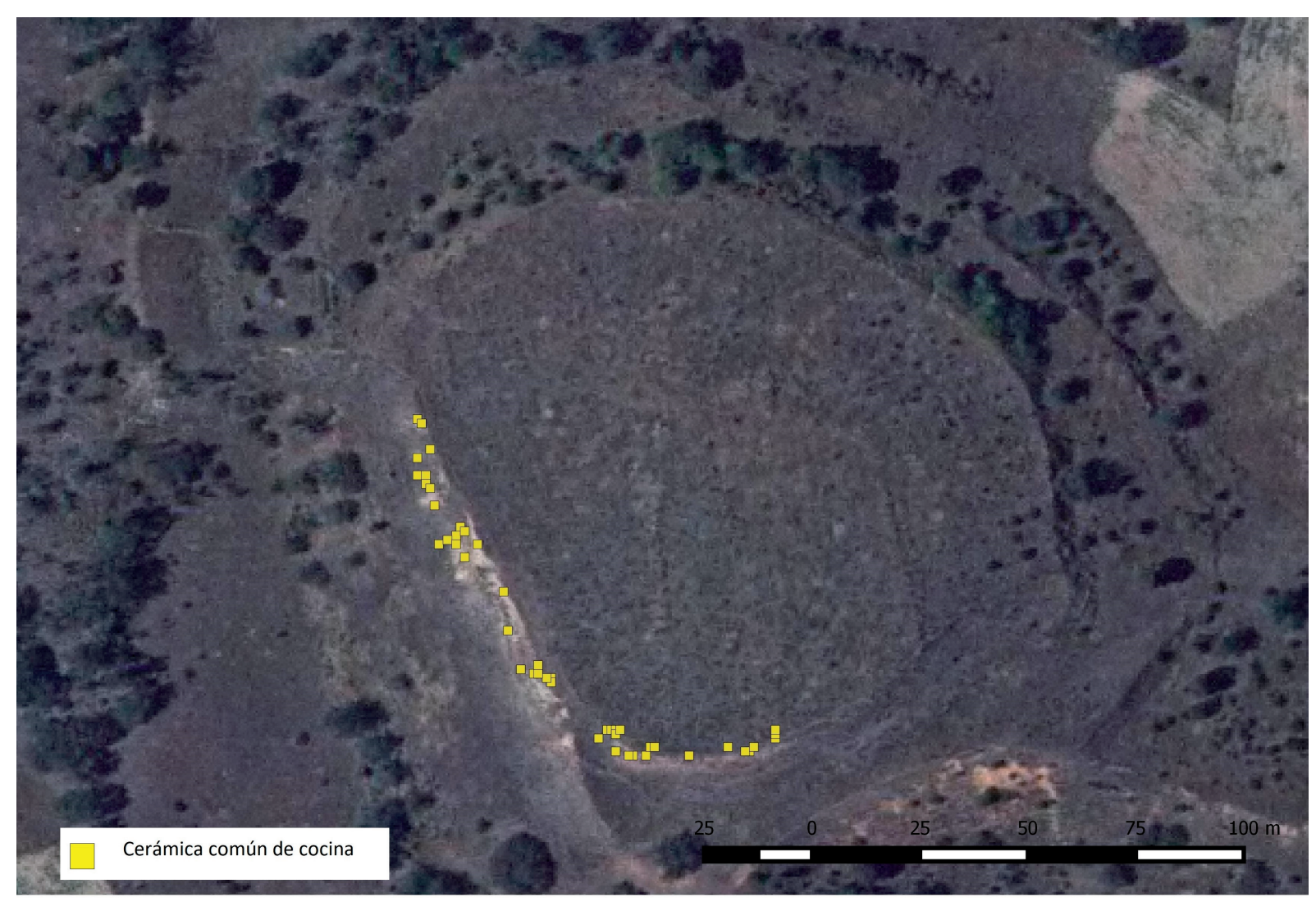

Figura 4. Castro de Pedredo (Santa Colomba de Somoza). Planta del asentamiento y dispersión de la cerámica común de cocina en el área prospectada. Base cartográfica del Instituto Geográfico Nacional (portal < http://pnoa.ign.es/>.).

\section{RESULTADOS DE LA PROSPECCIÓN. REGISTRO DEL MATERIAL CERÁMICO SUPERFICIAL}

\subsection{En el territorio de Asturica}

De los yacimientos seleccionados en territorio asturicense, hay dos que se pueden relacionar directamente con la explotación minera de la zona en época romana: la Corona del Castro y el yacimiento de Huerña-Los Linares. La Corona del Castro, también denominada como Castro de Pedredo-Alto de la Corona, es un lugar bien reconocible, pues destaca sobre el terreno y se localiza a unos $200 \mathrm{~m}$, al sureste de Pedredo (Orejas Saco del Valle 1996: 74-78, 117 y 194). La fotografía aérea permite apreciar la forma de la planta del asentamiento, sensiblemente circular, de unos $75 \mathrm{~m}$ de diámetro, con un recinto bien delimitado que cuenta, al parecer, con al menos un foso. El castro minero de época romana altoimperial se asentó sobre un espacio que ya había contado con una ocupación anterior, en la Edad del Hierro.
El contexto cerámico, aunque escaso, parece descartar una ocupación en época bajoimperial, ya que no se registra terra sigillata hispánica tardía. Sin embargo el hecho de que la producción más representada sea la cerámica común de cocina obliga a considerar la posibilidad de que exista una ocupación del asentamiento en el periodo suevo y visigodo (fig. 4, tab. 3).

En Huerña-Los Linares se identificó un poblado en llano de época altoimperial (siglos I-II), a partir de las excavaciones realizadas por Domergue y Martin (1977), que pusieron al descubierto estructuras de vivienda y un conjunto significativo de materiales. Se localiza al sur del Duerna y al oeste del río Llamas, en un espacio de minería intensamente explotado en la antigüedad (Orejas Saco del Valle 1996: 154 y 192). En el contexto cerámico superficial se obtienen, sin embargo, indicadores (terra sigillata hispánica tardía en cantidades significativas) que apuntan a una ocupación en fases más avanzadas. La ocupación del periodo suevo/ visigodo, queda marcada por un importante número de fragmentos de cerámica común de cocina asociada a la 
Tabla 3. Números totales y porcentajes (en gris) de las producciones cerámicas recuperadas en la prospección de Asturica. Cam: cerámica fabricada a mano, Cpint: cerámica pintada, Tsi: terra sigillata itálica, Tsg: terra sigillata gálica, Tsh: terra sigillata hispánica, Tsh avan: terra sigillata hispánica avanzada, Tsht lisa: terra sigillata hispánica tardía lisa, Tsh mold: terra sigillata hispánica tardía a molde, ARSW: African Red Slip Ware, CCCafr: cerámica común de cocina africana, Cpf: cerámica de paredes finas, Ceng: cerámica engobada, Cerp: cerámica de engobe rojo pompeyano, Cierp: imitación de la cerámica de engobe rojo pompeyano, CC: cerámica común, CCC: cerámica común de cocina, Cgn: cerámica de color gris o negro con superficies bruñidas, CCCb: cerámica común de cocina decorada con líneas bruñidas, CCb: cerámica común decorada con líneas bruñidas, Lu: lucernas, Mo: morteros, Lo: loza tradicional, lo ind: loza industrial y porcelana.

\begin{tabular}{|c|c|c|c|c|c|c|c|c|}
\hline Yacimiento & Cam & Cpint & Tsi & Tsg & Tsh & $\begin{array}{l}\text { Tsh } \\
\text { avan }\end{array}$ & $\begin{array}{l}\text { Tsht } \\
\text { lisa }\end{array}$ & $\begin{array}{l}\text { Tsht } \\
\text { mold }\end{array}$ \\
\hline \multirow{2}{*}{ Iglesia Caída } & 0,00 & 0,00 & 0,00 & 0,00 & 0,00 & 0,00 & 0,00 & 0,00 \\
\hline & 0,00 & 0,00 & 0,00 & 0,00 & 0,00 & 0,00 & 0,00 & 0,00 \\
\hline \multirow{2}{*}{ Regañón I } & 0,00 & 0,00 & 0,00 & 0,00 & 1,00 & 0,00 & 50,00 & 5,00 \\
\hline & 0,00 & 0,00 & 0,00 & 0,00 & 0,81 & 0,00 & 40,32 & 4,03 \\
\hline \multirow{2}{*}{ La Corona del Castro } & 1,00 & 0,00 & 0,00 & 0,00 & 10,00 & 0,00 & 0,00 & 0,00 \\
\hline & 1,15 & 0,00 & 0,00 & 0,00 & 11,49 & 0,00 & 0,00 & 0,00 \\
\hline \multirow{2}{*}{$\begin{array}{l}\text { Huerña- } \\
\text { Los Linares }\end{array}$} & 0,00 & 0,00 & 0,00 & 0,00 & 36,00 & 1,00 & 13,00 & 1,00 \\
\hline & 0,00 & 0,00 & 0,00 & 0,00 & 22,09 & 0,61 & 7,98 & 0,61 \\
\hline \multirow{2}{*}{ Brimeda } & 2,00 & 1,00 & 0,00 & 0,00 & 0,00 & 0,00 & 0,00 & 0,00 \\
\hline & 0,22 & 0,11 & 0,00 & 0,00 & 0,00 & 0,00 & 0,00 & 0,00 \\
\hline \multirow{2}{*}{ El Soldán } & 0,00 & 7,00 & 0,00 & 0,00 & 767,00 & 1,00 & 3,00 & 0,00 \\
\hline & 0,00 & 0,14 & 0,00 & 0,00 & 15,28 & 0,02 & 0,06 & 0,00 \\
\hline
\end{tabular}

\begin{tabular}{|l|c|c|c|c|c|c|c|c|}
\hline \multirow{2}{*}{ Yacimiento } & ARSW & $\begin{array}{c}\text { CCC } \\
\text { afr }\end{array}$ & Cpf & Ceng & Cerp & Cierp & CC & CCC \\
\hline \multirow{3}{*}{ Iglesia Caída } & 0,00 & 0,00 & 0,00 & 0,00 & 0,00 & 0,00 & 15,00 & 7,00 \\
\cline { 2 - 9 } & 0,00 & 0,00 & 0,00 & 0,00 & 0,00 & 0,00 & 65,22 & 30,43 \\
\hline \multirow{2}{*}{ Regañón I } & 0,00 & 0,00 & 0,00 & 0,00 & 2,00 & 1,00 & 31,00 & 17,00 \\
\cline { 2 - 9 } & 0,00 & 0,00 & 0,00 & 0,00 & 1,61 & 0,81 & 25,00 & 13,71 \\
\hline \multirow{2}{*}{ La Corona del Castro } & 0,00 & 0,00 & 1,00 & 0,00 & 0,00 & 0,00 & 24,00 & 48,00 \\
\cline { 2 - 9 } & 0,00 & 0,00 & 1,15 & 0,00 & 0,00 & 0,00 & 27,59 & 55,17 \\
\hline \multirow{2}{*}{ Huerña- } & 0,00 & 0,00 & 0,00 & 0,00 & 1,00 & 0,00 & 57,00 & 24,00 \\
\cline { 2 - 9 } & 0,00 & 0,00 & 0,00 & 0,00 & 0,61 & 0,00 & 34,97 & 14,72 \\
\hline \multirow{2}{*}{ Brimeda } & 0,00 & 0,00 & 0,00 & 0,00 & 0,00 & 0,00 & 215,00 & 10,00 \\
\cline { 2 - 9 } & 0,00 & 0,00 & 0,00 & 0,00 & 0,00 & 0,00 & 23,97 & 1,11 \\
\hline \multirow{2}{*}{ El Soldán } & 0,00 & 0,00 & 83,00 & 2,00 & 57,00 & 0,00 & $2.405,00$ & 1.670 \\
\cline { 2 - 9 } & 0,00 & 0,00 & 1,65 & 0,04 & 1,14 & 0,00 & 47,93 & 33,28 \\
\hline
\end{tabular}




\begin{tabular}{|l|c|c|c|c|c|c|c|c|}
\hline \multicolumn{1}{|c|}{ Yacimiento } & $\mathrm{Cgn}$ & $\mathrm{CCCb}$ & $\mathrm{CCb}$ & $\mathrm{Lu}$ & $\mathrm{Mo}$ & Lo & Lo ind & Total \\
\hline \multirow{3}{*}{ Iglesia Caída } & 0,00 & 0,00 & 0,00 & 0,00 & 0,00 & 1,00 & 0,00 & 23 \\
\cline { 2 - 10 } & 0,00 & 0,00 & 0,00 & 0,00 & 0,00 & 11,11 & 0,00 & 100 \\
\hline \multirow{2}{*}{ Regañón I } & 2,00 & 0,00 & 2,00 & 0,00 & 0,00 & 11,00 & 2,00 & 124 \\
\cline { 2 - 10 } & 1,61 & 0,00 & 1,61 & 0,00 & 0,00 & 8,87 & 1,61 & 100 \\
\hline \multirow{2}{*}{ La Corona del Castro } & 0,00 & 0,00 & 0,00 & 0,00 & 0,00 & 3,00 & 0,00 & 87 \\
\cline { 2 - 10 } & 0,00 & 0,00 & 0,00 & 0,00 & 0,00 & 3,45 & 0,00 & 100 \\
\hline \multirow{2}{*}{$\begin{array}{l}\text { Huerña- } \\
\text { Los Linares }\end{array}$} & 0,00 & 0,00 & 0,00 & 0,00 & 0,00 & 30,00 & 0,00 & 163 \\
\hline \multirow{2}{*}{ Brimeda } & 0,00 & 0,00 & 0,00 & 0,00 & 0,00 & 18,40 & 0,00 & 100 \\
\hline \multirow{2}{*}{ El Soldán } & 0,00 & 0,00 & 50,00 & 0,00 & 0,00 & 345,00 & 274,00 & 897 \\
\hline
\end{tabular}

presencia de terra sigillata hispánica tardía a molde, ya que esta producción empieza a fabricarse en las últimas décadas del siglo IV (López Rodríguez 1985: 140 y 245-46, Paz Peralta 1991: 104, 117-19 y 228; 2008: 506-7; Dahí Elena 2007 y 2012) (fig. 5, tab. 3).

Sin aparente relación con la actividad minera, el yacimiento de Iglesia Caída destaca como un pequeño espacio elevado de forma aproximadamente circular, de c $75 \mathrm{~m}$ de diámetro, localizado a un kilómetro al oeste de Vega de Magaz. De hecho, es la morfología del asentamiento lo que justifica la catalogación del sitio como castro. Los materiales obtenidos en el muestreo, en condiciones de mala visibilidad, son suficientes para postular la existencia de poblamiento en Iglesia Caída, pero no permiten definir una secuencia cultural precisa, aunque la asociación de cerámica común de cocina y cerámica común, como únicas producciones significativas recuperadas, apunta a una ocupación alto y plenomedieval, que podría ser continuadora de la secuencia romana, en gran medida dudosa, definida tan solo por la morfología del asentamiento (fig. 6, tab. 3).

Prospectamos también un yacimiento, Regañón I, cuya tipología por el momento está por determinar, ya que la superficie de dispersión de material es muy reducida e incompatible con la lectura del yacimiento como villa romana. El contexto cerámico obtenido define una secuencia de ocupación en el Bajo Imperio (con seguridad en el siglo IV, aunque podría remontar a un momento impreciso del siglo III), a juzgar por el importante número de fragmentos de terra sigillata hispánica tardía. El hallazgo de cinco fragmentos de la variante a molde de esta producción junto a la presencia de dos fragmentos de cerámica de color gris o negro con superficie bruñida son argumentos para proponer una ocupación del lugar en la primera mitad del siglo V (Ariño Gil y Dahí Elena 2012, Dahí Elena 2012: 224). Un fragmento de cerámica a molde con barniz rojo-pompeyano podría ser indicativo de una fase más avanzada (Ariño Gil y Dahí Elena 2012, Dahí Elena 2012: 225), pero el escaso número recuperado de fragmentos de cerámica común de cocina es una evidencia que argumenta en contra de una secuencia de ocupación en el periodo visigodo avanzado (fig. 7, tab. 3).

Como hemos señalado antes, el hábitat tipo villa está representado por el yacimiento de El Soldán, de hecho, la única villa bien documentada en el territorio asturicense. La clasificación y cuantificación del material cerámico procedente de las excavaciones practicada a principios del siglo XX documenta un periodo de ocupación del asentamiento bastante reducido, entre la época flavia y los inicios del siglo III. Entre las producciones de mesa domina de forma casi exclusiva la terra sigillata hispánica lisa y a molde. Aunque la bibliografía recoge la presencia de dos fragmentos de terra sigillata gálica (Mañanes Pérez 1977: 228, Gorges 1979: 276-277) estas piezas no se encontraban entre los materiales que pudimos examinar. La terra sigillata hispánica tardía está prácticamente ausente (tan solo se contabilizan tres fragmentos de la variedad lisa). La producción más representada es la cerámica común, 


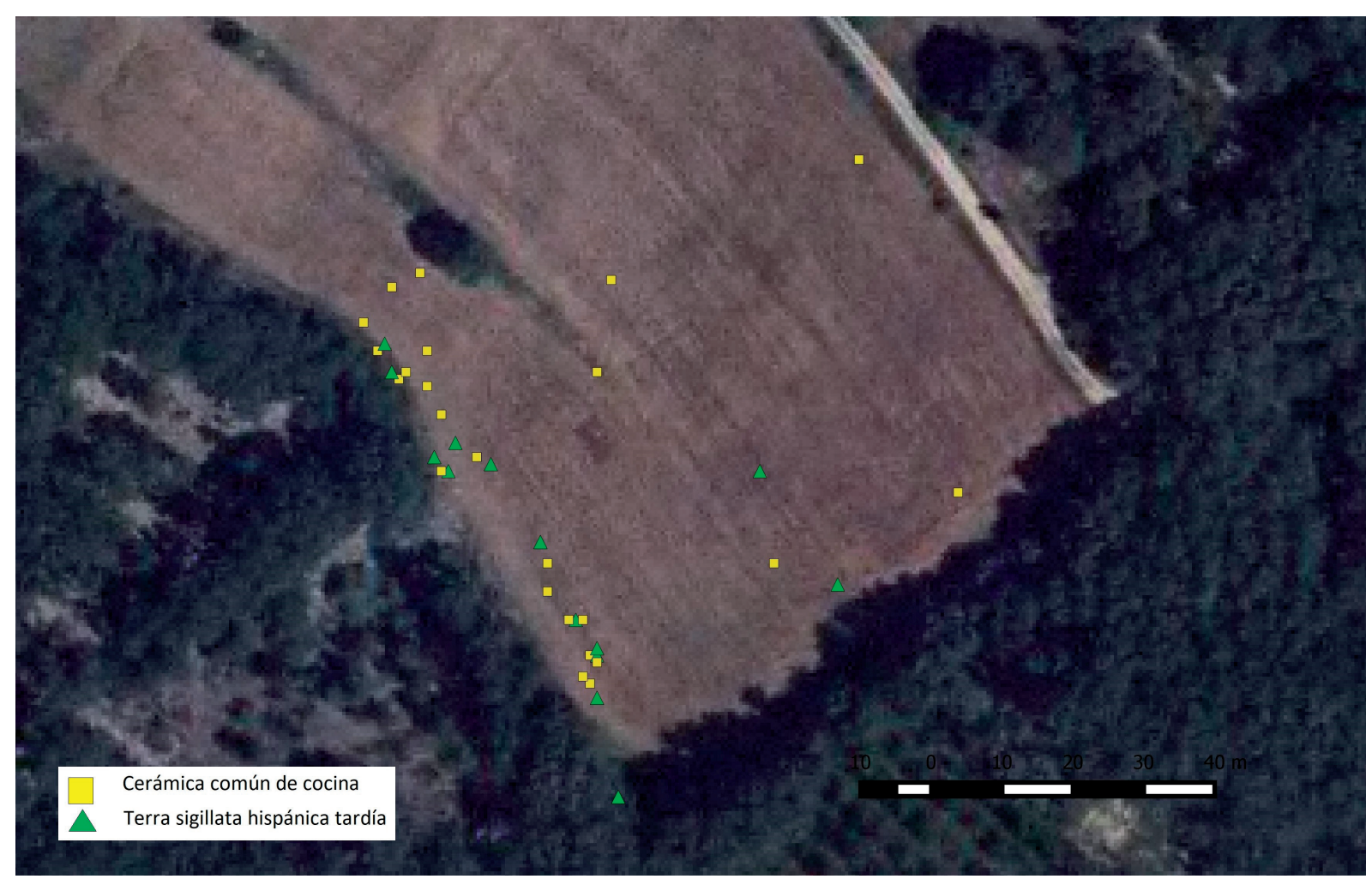

Figura 5. Huerña-Los Linares (Luyego). Dispersión de la terra sigillata hispánica tardía y de la cerámica común de cocina en el área prospectada. Base cartográfica del Instituto Geográfico Nacional (portal http://pnoa.ign.es/).

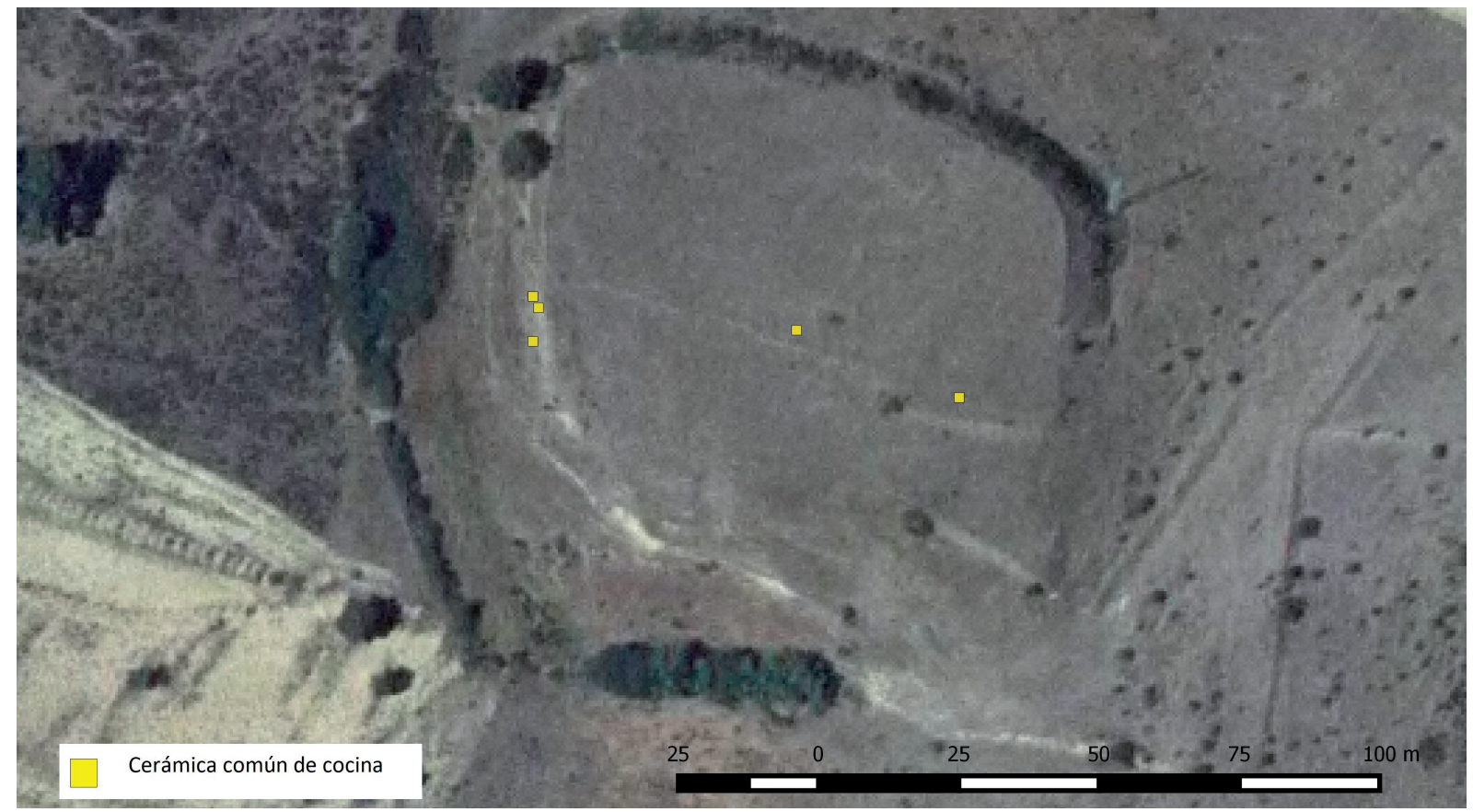

Figura 6. Iglesia Caída (Magaz de Cepeda). Planta del asentamiento y dispersión de la cerámica común de cocina en el área prospectada. Base cartográfica del Instituto Geográfico Nacional (portal http://pnoa.ign.es/).el área prospectada. Base cartográfica del Instituto Geográfico Nacional (portal http://pnoa.ign.es/). 


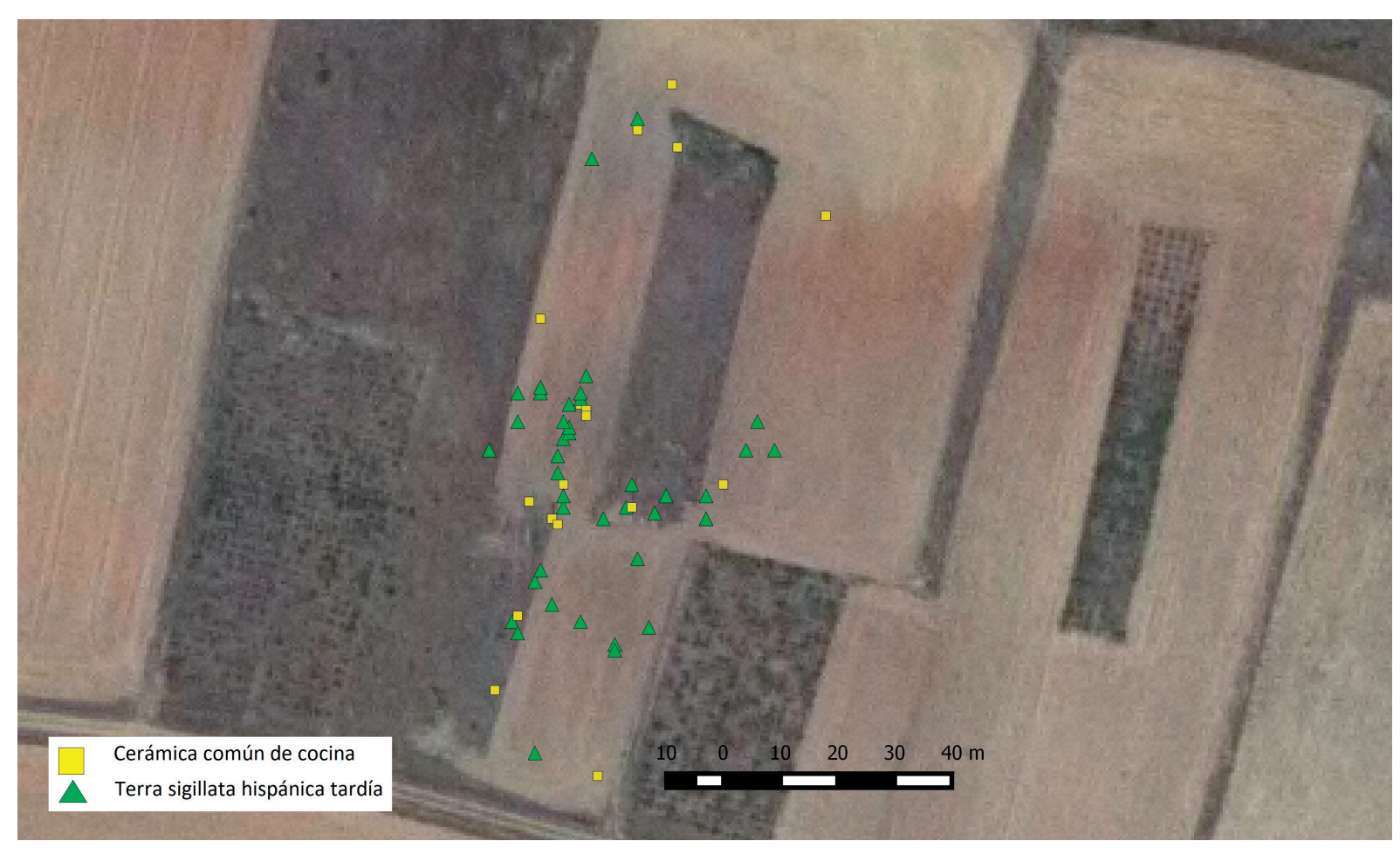

Figura 7. Regañón I (Villaobispo de Otero). Dispersión de la cerámica común de cocina y de terra sigillata hispánica tardía en el área prospectada. Base cartográfica del Instituto Geográfico Nacional (portal http://pnoa.ign.es/).

tanto con cocciones reductoras como oxidantes. La cerámica común de cocina presenta valores muy altos, pero dado que es el único indicio que podría apuntar a una ocupación tardía, lo más probable es que esta producción haya que situarla también en el periodo romano altoimperial. El examen del conjunto cerámico revela que no existen indicadores seguros que avalen la ocupación del asentamiento en la secuencia sueva, visigoda o altomedieval (tab. 3).

El muestreo del material off-site en el parcelario regular del entorno de Brimeda aporta importante información sobre el proceso de colonización del espacio agrícola en época altomedieval. Los indicios de ocupación del suelo antes del periodo en que se funda la villa son casi inexistentes y concuerdan con el hecho de que la colonización se hiciera sobre tierras prácticamente vírgenes, tal como describe el documento. En todo el espacio muestreado no se detectó ni un solo enclave previo e incluso el material registrado que podría datar de una fase anterior a la colonización emprendida por el obispo de Asturica se reduce a dos fragmentos de tegulae. Algunos de los fragmentos de cerámica común de cocina (diez en total) presentan fábricas características de las producciones del periodo suevo y visigodo, aunque no son incompatibles con contextos del siglo IX. Sin embargo el dato más importante lo aporta el hallazgo de 50 fragmentos de cerámica común decorada con líneas bruñidas, entre las que cabe destacar que existe una variación en esta técnica decorativa más cercana al espatulado con un instrumento de poca anchura (figs. 8 y 9, tab. 3). Estas cerámicas suelen considerarse como propias del periodo plenomedieval, asociándose a la segunda mitad del siglo XII, basándose para ello, fundamentalmente, en el registro del alfar de La Morterona (Saldaña) donde se asocian a una moneda de Sancho III (Peñil Mínguez 1987). No obstante la exacta cronología de esta producción cerámica está por establecer. Se sabe que se prolonga más allá de esta fecha-pues aparece por ejemplo en un contexto datado en el siglo XIII en el alfar de la calle Duque de la Victoria de Valladolid (Villanueva Zubizarreta 2011: 98-100)-, pero también se han propuesto dataciones en fases anteriores, en torno a los siglos IX-XI (Martínez Peñín 2007: 173-174). Por otro lado, su relación con la cerámica común de cocina decorada con líneas bruñidas, característica de la secuencia final del periodo visigodo (Dahí Elena 2012: 224-225) es un asunto pendiente de determinar, dado que la técnica decorativa es la misma en ambas producciones. 


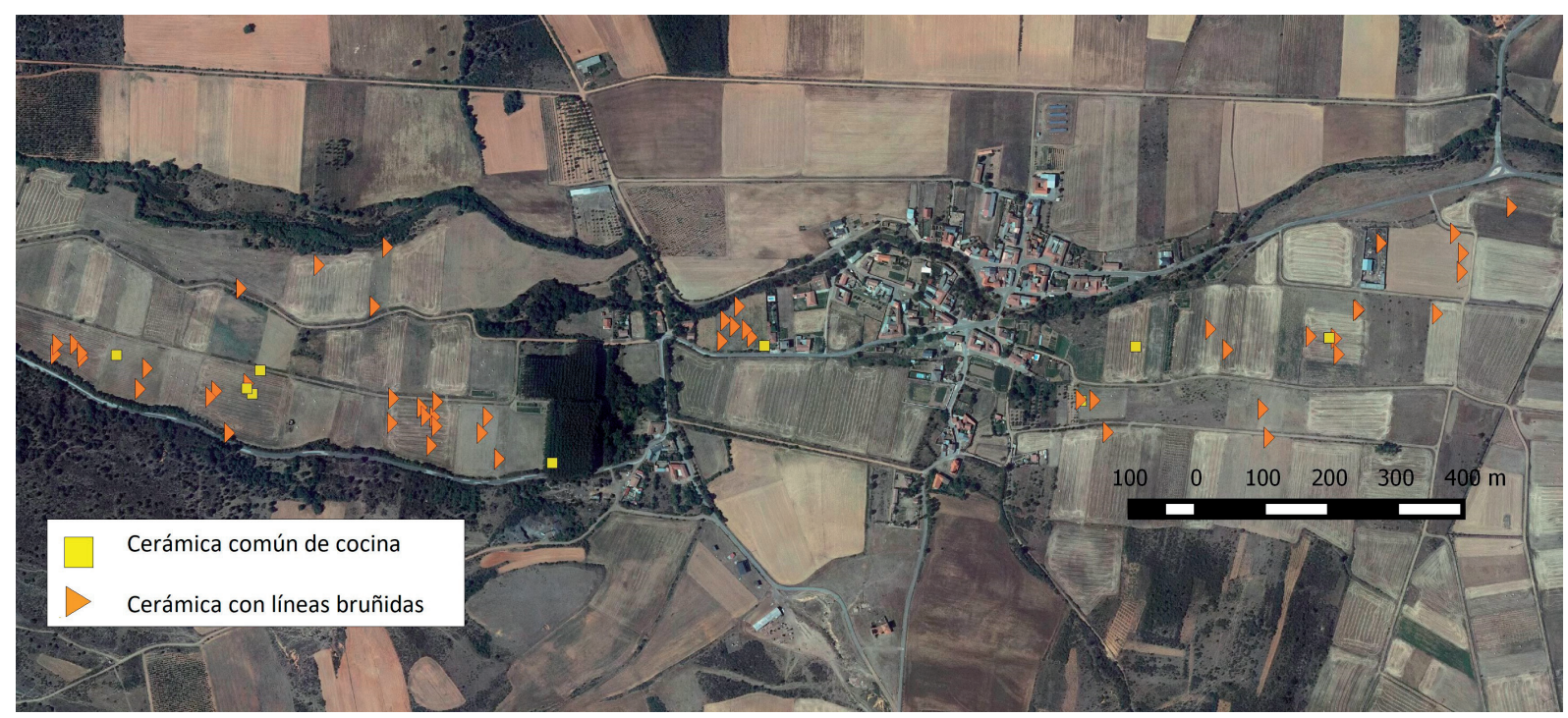

Figura 8. Brimeda (Villaobispo de Otero). Dispersión de la cerámica común decorada con líneas bruñidas en el área prospectada. Base cartográfica del Instituto Geográfico Nacional (portal http://pnoa.ign.es/).

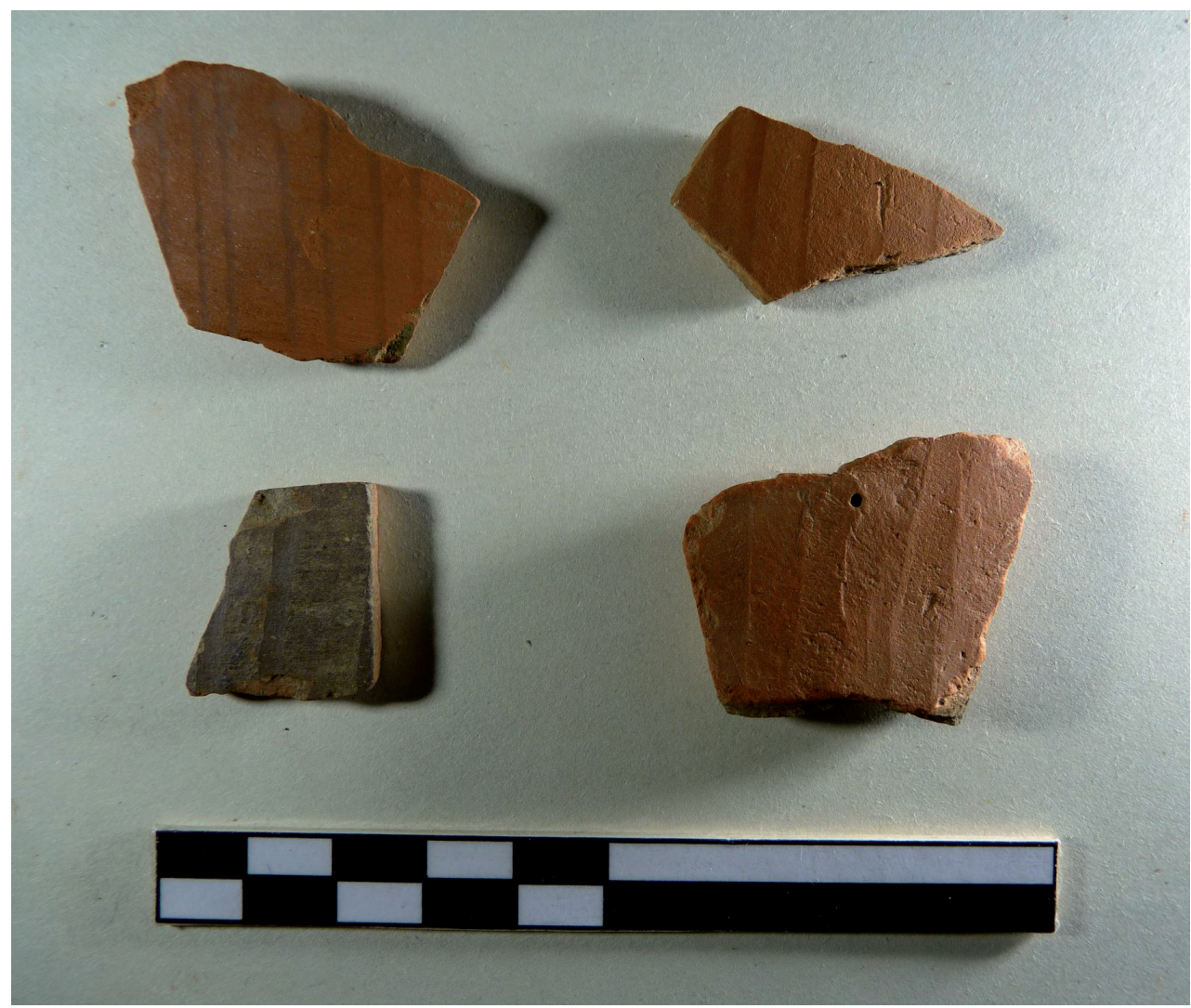

Figura 9. Brimeda (Villaobispo de Otero). Producciones de cerámica común decoradas con líneas bruñidas recuperadas en el muestreo.

ISSN: $1133-4525 \quad$ ISSN-e: $2255-3924$ 


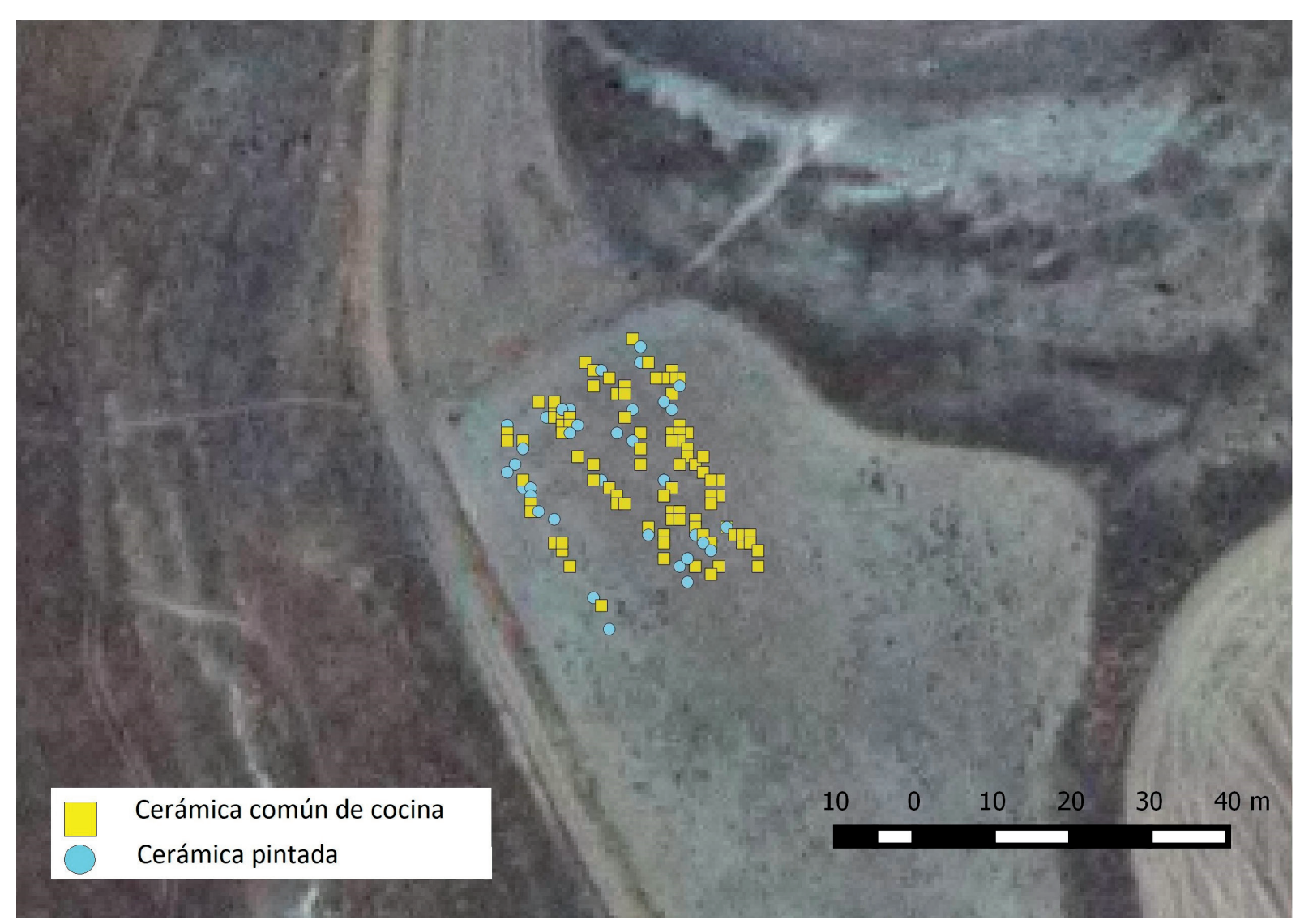

Figura 10. Teso de la Mora (Molacillos). Dispersión de la cerámica pintada de tipo celtibérico y de la cerámica común de cocina en el área prospectada. Base cartográfica del Instituto Geográfico Nacional (portal http://pnoa.ign.es/).

\subsection{En el territorio de Albocela.}

En el territorio de Albocela se prospectaron dos asentamientos en altura, uno de ellos (el Teso de la Mora) con una posible continuación del hábitat entre el periodo prerromano y romano y otro (el Castro del Viso) que parecía haber estado deshabitado durante el periodo romano y ocupado, de nuevo, en el periodo altomedieval. El primero de ellos, el Teso de la Mora, pese a la evidencia de las cisternas romanas, a los resultados positivos obtenidos en las excavaciones practicadas por Balado Pachón y Martínez García (2008) y a que la inspección fue realizada con la superficie con buenas condiciones de visibilidad, no presentaba material cerámico en la parte alta y plana del cerro, donde presumiblemente se habría establecido el hábitat. No obstante en la ladera meridional del teso, al este del camino de acceso al conjunto arqueológico, se detectó un espacio que presentaba un significativo conjunto de cerámica en superficie y fue en esta zona donde se practicó el muestreo (fig. 10, tab. 4).
En el muestreo se recuperaron fragmentos de cerámica a mano, asociados quizá a una secuencia de la I Edad del Hierro. También un número significativo de fragmentos de cerámica pintada con motivos de líneas en arcos trazados a compás, de tipo celtibérico. El hallazgo de estas dos producciones aparentemente confirma la interpretación del Teso de la Mora como un castro con ocupación en la Edad del Hierro. Esta lectura debe enfrentarse, sin embargo, al hecho de que no se hayan documentado restos de muralla ni restos cerámicos en la zona alta del cerro y, sobre todo, a que las excavaciones practicadas en la parte alta del teso hayan revelado niveles de la Edad del Hierro de muy escasa potencia y asociados sobre todo al conjunto donde se localizan las cisternas romanas. La exacta tipología del asentamiento queda por definir, pero es posible que el hábitat romano al que abastecerían las cisternas haya que localizarlo a los pies del cerro. Por lo que respecta a la ocupación tardía, el importante conjunto de cerámica común de cocina recogido en la zona del muestreo 
Tabla 4. Números totales y porcentajes (en gris) de las producciones cerámicas recuperadas en la prospección de Albocela. Cam: cerámica fabricada a mano, Cpint: cerámica pintada, Tsi: terra sigillata itálica, Tsg: terra sigillata gálica, Tsh: terra sigillata hispánica, Tsh avan: terra sigillata hispánica avanzada, Tsht lisa: terra sigillata hispánica tardía lisa, Tsh mold: terra sigillata hispánica tardía a molde, ARSW: African Red Slip Ware, CCCafr: cerámica común de cocina africana, Cpf: cerámica de paredes finas, Ceng: cerámica engobada, Cerp: cerámica de engobe rojo pompeyano, Cierp: imitación de la cerámica de engobe rojo pompeyano, CC: cerámica común, CCC: cerámica común de cocina, Cgn: cerámica de color gris o negro con superficies bruñidas, CCCb: cerámica común de cocina decorada con líneas bruñidas, CCb: cerámica común decorada con líneas bruñidas, Lu: lucernas, Mo: morteros, Lo: loza tradicional, lo ind: loza industrial y porcelana.

\begin{tabular}{|c|c|c|c|c|c|c|c|c|}
\hline Yacimiento & Cam & Cpint & Tsi & Tsg & Tsh & Tsh avan & Tsht & Tsht mold \\
\hline \multirow{2}{*}{ Teso de la Mora } & 25,00 & 39,00 & 1,00 & 0,00 & 0,00 & 0,00 & 0,00 & 0,00 \\
\hline & 6,94 & 10,83 & 0,28 & 0,00 & 0,00 & 0,00 & 0,00 & 0,00 \\
\hline \multirow{2}{*}{ Castro del Viso } & 19,00 & 12,00 & 0,00 & 0,00 & 0,00 & 0,00 & 0,00 & 0,00 \\
\hline & 4,36 & 2,75 & 0,00 & 0,00 & 0,00 & 0,00 & 0,00 & 0,00 \\
\hline \multirow{2}{*}{ EI Toro-Tejadillo } & 0,00 & 0,00 & 0,00 & 0,00 & 19,00 & 0,00 & 53,00 & 8,00 \\
\hline & 0,00 & 0,00 & 0,00 & 0,00 & 5,72 & 0,00 & 15,96 & 2,41 \\
\hline \multirow{2}{*}{ Tímulos } & 66 & 0,00 & 0,00 & 0,00 & 0,00 & 0,00 & 0,00 & 0,00 \\
\hline & 27,27 & 0,00 & 0,00 & 0,00 & 0,00 & 0,00 & 0,00 & 0,00 \\
\hline \multirow{2}{*}{ El Cementerio } & 0,00 & 0,00 & 0,00 & 0,00 & 27,00 & 0,00 & 52,00 & 12,00 \\
\hline & 0,00 & 0,00 & 0,00 & 0,00 & 5,49 & 0,00 & 10,57 & 2,44 \\
\hline
\end{tabular}

\begin{tabular}{|l|c|c|c|c|c|c|c|c|}
\hline \multicolumn{1}{|c|}{ Zona } & ARSW & CCC afr & Cpf & Ceng & Cerp & Cierp & CC & CCC \\
\hline \multirow{3}{*}{ Teso de la Mora } & 0,00 & 0,00 & 1,00 & 0,00 & 1,00 & 0,00 & 193,00 & 100,00 \\
\cline { 2 - 10 } & 0,00 & 0,00 & 0,28 & 0,00 & 0,28 & 0,00 & 53,61 & 27,78 \\
\hline \multirow{2}{*}{ Castro del Viso } & 0,00 & 1,00 & 0,00 & 1,00 & 0,00 & 0,00 & 152,00 & 239,00 \\
\cline { 2 - 10 } & 0,00 & 0,23 & 0,00 & 0,23 & 0,00 & 0,00 & 34,86 & 54,82 \\
\hline \multirow{3}{*}{ El Toro-Tejadillo } & 0,00 & 1,00 & 8,00 & 1,00 & 1,00 & 0,00 & 81,00 & 119,00 \\
\cline { 2 - 10 } & 0,00 & 0,30 & 2,41 & 0,30 & 0,30 & 0,00 & 24,40 & 35,84 \\
\hline \multirow{2}{*}{ El Cemulos } & 0,00 & 0,00 & 0,00 & 0,00 & 0,00 & 0,00 & 112,00 & 44,00 \\
\cline { 2 - 10 } & 0,00 & 0,00 & 0,00 & 0,00 & 0,00 & 0,00 & 46,28 & 18,18 \\
\hline
\end{tabular}




\begin{tabular}{|l|c|c|c|c|c|c|c|c|}
\hline \multirow{2}{*}{ Zona } & $\mathrm{Cgn}$ & $\mathrm{CCCb}$ & $\mathrm{CCb}$ & $\mathrm{Lu}$ & $\mathrm{Mo}$ & Lo & Lo ind/ & Total \\
\hline \multirow{3}{*}{ Teso de la Mora } & 0,00 & 0,00 & 0,00 & 0,00 & 0,00 & 0,00 & 0,00 & 360 \\
\cline { 2 - 11 } & 0,00 & 0,00 & 0,00 & 0,00 & 0,00 & 0,00 & 0,00 & 100 \\
\hline \multirow{2}{*}{ Castro del Viso 2 } & 0,00 & 0,00 & 1,00 & 0,00 & 0,00 & 11,00 & 0,00 & 436 \\
\cline { 2 - 11 } & 0,00 & 0,00 & 0,23 & 0,00 & 0,00 & 2,52 & 0,00 & 100 \\
\hline \multirow{2}{*}{ El Toro-Tejadillo } & 0,00 & 0,00 & 5,00 & 0,00 & 0,00 & 34,00 & 2,00 & 332 \\
\cline { 2 - 11 } & 0,00 & 0,00 & 1,51 & 0,00 & 0,00 & 10,24 & 0,60 & 100 \\
\hline \multirow{2}{*}{ Tímulos } & 0,00 & 5,00 & 11,00 & 0,00 & 0,00 & 3,00 & 1,00 & 242 \\
\cline { 2 - 10 } & 0,00 & 2,07 & 4,55 & 0,00 & 0,00 & 1,24 & 0,41 & 100 \\
\hline \multirow{2}{*}{ El Cementerio } & 0,00 & 1,00 & 0,00 & 0,00 & 0,00 & 17,00 & 0,00 & 492 \\
\cline { 2 - 10 } & 0,00 & 0,20 & 0,00 & 0,00 & 0,00 & 3,46 & 0,00 & 100 \\
\hline
\end{tabular}

se interpreta como un indicio de ocupación fechada en el periodo suevo/visigodo, si bien no aparece ninguna de las otras producciones significativas de este periodo, siendo llamativa la ausencia de terra sigillata hispánica tardía a molde, habitual en los contextos del siglo V, lo que apunta a una datación del conjunto de la cerámica común de cocina en una fase avanzada del periodo visigodo, algo que se refuerza por la ausencia de tegulae en la zona del muestreo, la cual se limita a un único fragmento. La ocupación tardía, a juzgar por los datos obtenidos, no es general y no afecta a la parte alta del cerro.

El segundo ejemplo, el Castro del Viso, es un cerro testigo que se eleva de forma significativa sobre el terreno circundante. La cima amesetada, donde las intervenciones anteriores habían detectado restos arqueológicos atribuibles a la Edad del Hierro (Martín Valls 1973: 403-405, 1995: 154-157 y 172), se encontraba cubierta de vegetación en el momento de la prospección. No obstante, pudo recuperarse un conjunto cerámico -que juzgamos representativo de la ocupación- muestreando en espacios reducidos con buena visibilidad. El yacimiento responde por su tipología a un asentamiento tipo castro, algo que también está respaldado por la significativa presencia de fragmentos de cerámica a mano y de cerámicas pintadas de tipo celtibérico, repartidas en toda la superficie muestreada. La ocupación del periodo suevo/visigodo está argumentada por el importante número de fragmentos recuperados de la producción de cerámica común de cocina, con fábricas características de este periodo. Aunque no se recupera terra sigillata hispánica tardía, sí aparecen en la proporción habitual, casi testimonial, algunas de las producciones de tradición romana que habitualmente se recuperan en los contextos cerámicos del periodo suevo/visigodo, en este caso la cerámica engobada y la cerámica de cocina africana, ambas representadas por un único fragmento (fig. 10, tab. 4).

Las dos villae que pudimos muestrear en el territorio de Albocela dieron resultados interesantes. Por un lado, El Toro-Tejadillo ofreció un perfil cerámico -con terra sigillata hispánica, cerámica de paredes finas, cerámica engobada y cerámica de engobe rojo pompeyano-, que es sin duda el característico de una villa romana con ocupación desde el Alto Imperio (quizá en torno a finales del siglo I o principios del II) hasta el periodo suevo/visigodo (a juzgar por el número importante de fragmentos de cerámica común de cocina y la significativa presencia de terra sigillata hispánica tardía a molde, que remite al menos a la primera mitad del siglo V). No existen indicadores cualitativos que aporten más información, aunque la recuperación de un fragmento de tegula mammata (que apunta a la existencia de un espacio termal) es concordante con la interpretación del yacimiento como una villa romana que prolonga su ocupación a lo largo de los periodos suevo y visigodo (tab. 4).

Como en el caso de El Toro-Tejadillo, los restos superficiales detectados en El Cementerio ocupaban una amplia extensión y se encontraban en buenas condiciones de visibilidad. El contexto cerámico de El Cementerio es, de hecho, muy similar al de El Toro-Tejadillo - con terra sigillata hispánica, cerámica de paredes finas, cerámica engobada y cerámica de engobe rojo pompeyano- y señala del mismo modo una ocupación 


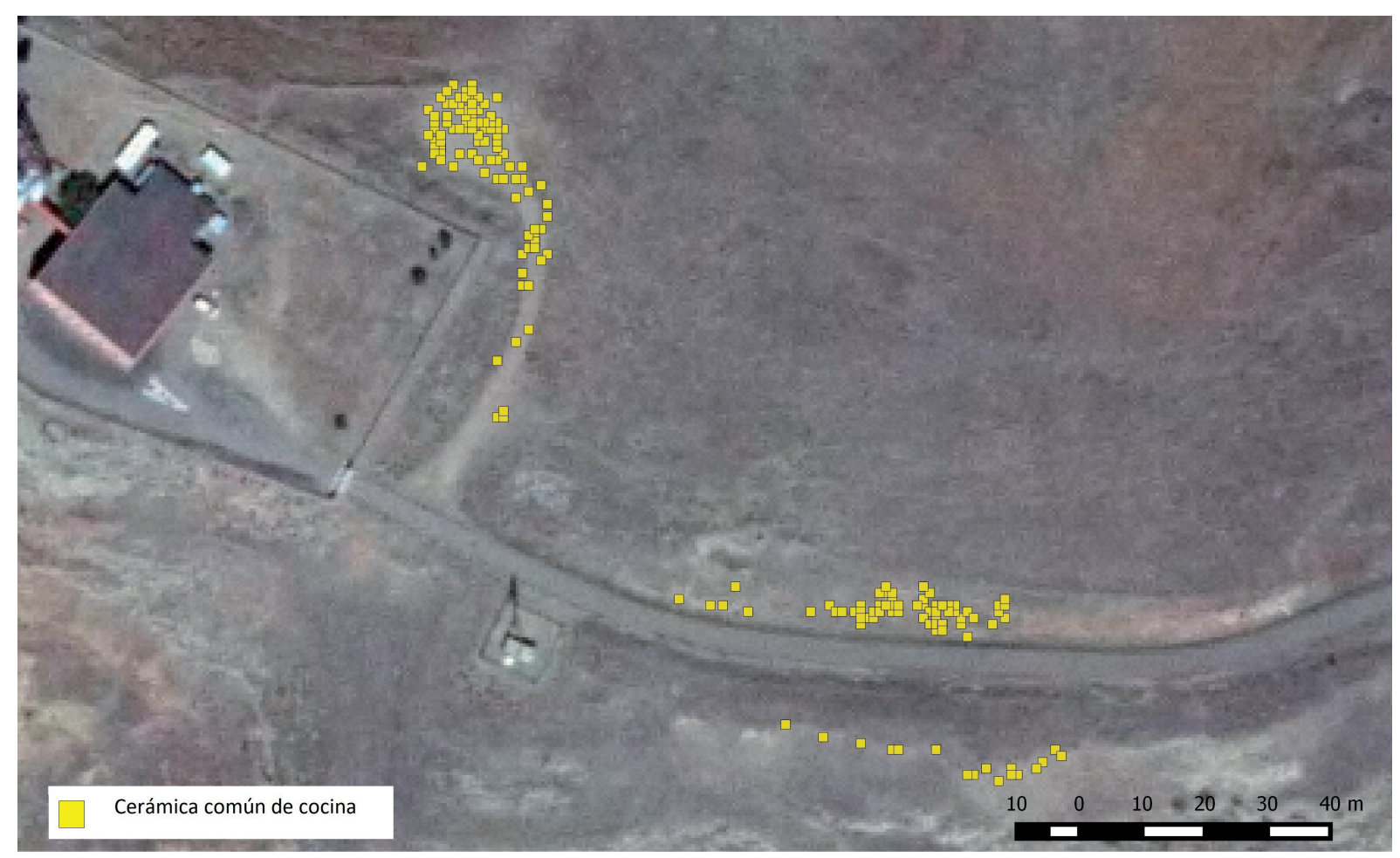

Figura 11. Castro del Viso (Madridanos). Dispersión de la cerámica común de cocina en el área prospectada. Base cartográfica del Instituto Geográfico Nacional (portal http://pnoa.ign.es/).

que se inicia en torno a finales del siglo I o principios del II, hasta el periodo suevo/visigodo, con al menos un fragmento de cerámica común de cocina decorada con líneas bruñidas que remite a fechas posteriores a mediados del siglo VI (Dahí Elena 2012: 224-225) (tab. 4).

Por último hay que referirse al yacimiento de Tímulos, asentamiento que fue seleccionado como representativo del hábitat tardío y altomedieval en llano. El topónimo remite a un caserío localizado en la margen izquierda del río Duero, al sur de Toro. A unos $150 \mathrm{~m}$ al sur del caserío se detectó una estructura que, aunque transformada en palomar, responde sin ninguna duda a la tipología de un monumento funerario romano en un apreciable estado de conservación, con muros de opus caementicium y sillares angulares en piedra formando un cuerpo inferior prismático (fig. 11). La prospección previa no detectó, sin embargo, restos cerámicos asociados a esta construcción. En cambio sí se obtuvo un contexto cerámico superficial importante en la zona de huertas y viñas inmediatas a los edificios más meridionales del caserío y fue allí donde se practicó el muestreo.

En Tímulos existen argumentos para considerar la existencia de una ocupación en el Bronce Medio, a juzgar por el significativo número de piezas cerámicas a mano, algunas de ellas con decoraciones características de ese periodo (se reconocen rasgos de las culturas de Proto-Cogotas y Cogotas I). No se documentan materiales del periodo romano, pese a que según nuestra lectura, los restos arquitectónicos detectados a unos $150 \mathrm{~m}$ de la zona del muestreo se identifican con un monumento funerario romano. Sí hay indicios, aunque débiles, para proponer una ocupación del espacio en el periodo visigodo avanzado, a juzgar por la cerámica común de cocina (con fábricas características de esta fase) junto a cinco fragmentos de la variante de esta misma producción decorada con líneas bruñidas, la cual no aparece en los registros antes de mediados del siglo VI (Dahí Elena 2012: 224-225) (fig. 12, tab. 4). Más clara es aún la secuencia medieval plena, representada por la cerámica común decorada con líneas bruñidas. Suele admitirse que esta producción marca niveles plenomedievales, en torno a la segunda mitad del siglo XII (Peñil Mínguez 1987, Bohígas Roldán 1990), si bien no se ha establecido una fecha para el origen de esta producción, que podría ser más temprana (Martínez Peñín 2007). La presencia de esta producción es concordante con la documentación que recoge el lugar en la toponimia del año 1208 (Pascual Sánchez 1991: 198-199). Tímulos es 


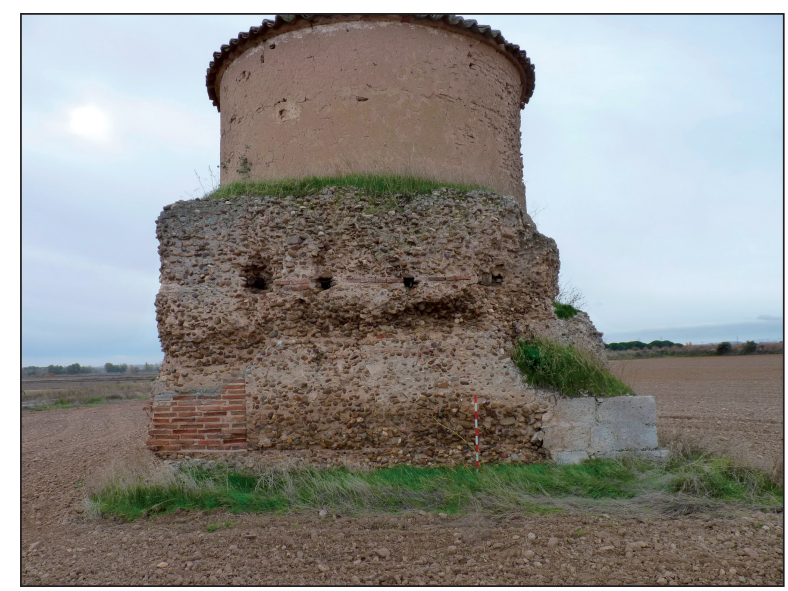

Figura 12. Tímulos (Toro). Edificación interpretada como un monumento funerario de época romana.

un caso único en el que el hábitat del periodo suevo y visigodo se prolonga hasta el periodo medieval, perviviendo como espacio ocupado hasta hoy.

\section{INTERPRETACIÓN FINAL Y CONCLUSIONES}

La investigación que hemos llevado a cabo pretendía analizar el comportamiento y evolución de los asentamientos rurales en el periodo entre la Antigüedad Tardía y la Alta Edad Media en dos ciudades con trayectorias diferentes. Los resultados obtenidos (bien es cierto que sobre el número limitado de yacimientos que han sido objeto de muestreo) parecen indicar que el hábitat rural del periodo post-romano y altomedieval responde a su propia dinámica y esta es independiente de la supervivencia o no del núcleo urbano del que depende.

En ambos casos de estudio ha podido observarse la reactivación de los lugares en altura con ocupación en fases precedentes. En el territorio de Albocela, ciudad completamente abandonada en el siglo V, este fenómeno se aprecia tanto en el Teso de la Mora como en el Castro del Viso, pese a que las secuencias de ocupación de ambos son algo diferentes. Mientras que en el Teso de la Mora la ocupación previa al periodo suevo/visigodo está marcada sobre todo por la presencia de dos cisternas romanas (y quizá por una ocasional ocupación en la Edad del Hierro mal documentada), el Castro del Viso puede considerarse un castro de la Edad del Hierro prototípico. En el territorio asturicense, este fenómeno aparece en el Castro de Pedredo, el cual presenta secuencias de ocupación en la Edad del Hierro y en el periodo romano, perviviendo en el periodo suevo/visigodo. El yacimiento de Iglesia Caída podría entrar en la misma categoría, si bien en este asentamiento solo la secuencia altomedieval está atestiguada en el muestreo.

Con la información disponible no es posible establecer si la ocupación de estos asentamientos en altura es continuista con las fases anteriores o responde a fenómenos de reocupación, si bien hay que señalar que en tres de los casos analizados (la excepción la constituye Castro de Pedredo) se aprecia un hiato en la secuencia, faltando en los contextos la terra sigillata hispánica altoimperial. El fenómeno documentado en estos asentamientos es, aparentemente, algo diferente al de los asentamientos en altura de nueva creación que la arqueología está identificando en todo el paisaje rural hispano en los periodos suevo y visigodo (Ariño Gil 2013, Martín Viso 2006, Diarte-Blasco 2018: 70-75), siendo especialmente característico del noroeste hispánico (Quirós Castillo 2011: 291-293) y quizá relacionado con la gestión del espacio de frontera entre los reinos suevo y visigodo (Ariño Gil y Díaz 2014), así como con la ausencia de un número significativo de centros urbanos que ejerzan el rol de lugares centrales en el territorio.

Otro fenómeno característico de las secuencias sueva y visigoda es el de la creación de asentamientos rurales en llano (Vigil-Escalera 2007 y 2009, Quirós Castillo 2013), lo que también se documenta en los dos territorios de estudio. En Albocela aparece en el yacimiento de Tímulos, el cual parece tener como referencia no un espacio de hábitat previo, sino un monumento funerario romano, algo que pone de manifiesto la gran complejidad que reviste el análisis de los fenómenos de continuidad/discontinuidad entre el hábitat del periodo suevo/visigodo y el precedente romano (Ariño Gil 2013: 94-95). Tímulos es un asentamiento altamente singular ya que, de todos los casos analizados, es el único centro rural habitado en los periodos suevo y visigodo que sobrevive a lo largo de la Edad Media y continúa poblado hasta hoy, si bien como caserío y no como municipio. En Asturica los pequeños asentamientos en llano están representados por el yacimiento de Regañón I, un hábitat rural de pequeña entidad con origen en el periodo romano tardío (en torno a los siglos III o IV), pero también en un asentamiento de tipo minero como es Huerña-Los Linares, característico del hábitat altoimperial vinculado a la extracción de oro. La pervivencia de ocupación de la villa en la secuencia sueva y visigoda (pero sin prolongación en los siglos siguientes) aparece bien atestiguada en el caso de Albocela, con los casos emblemáticos de 


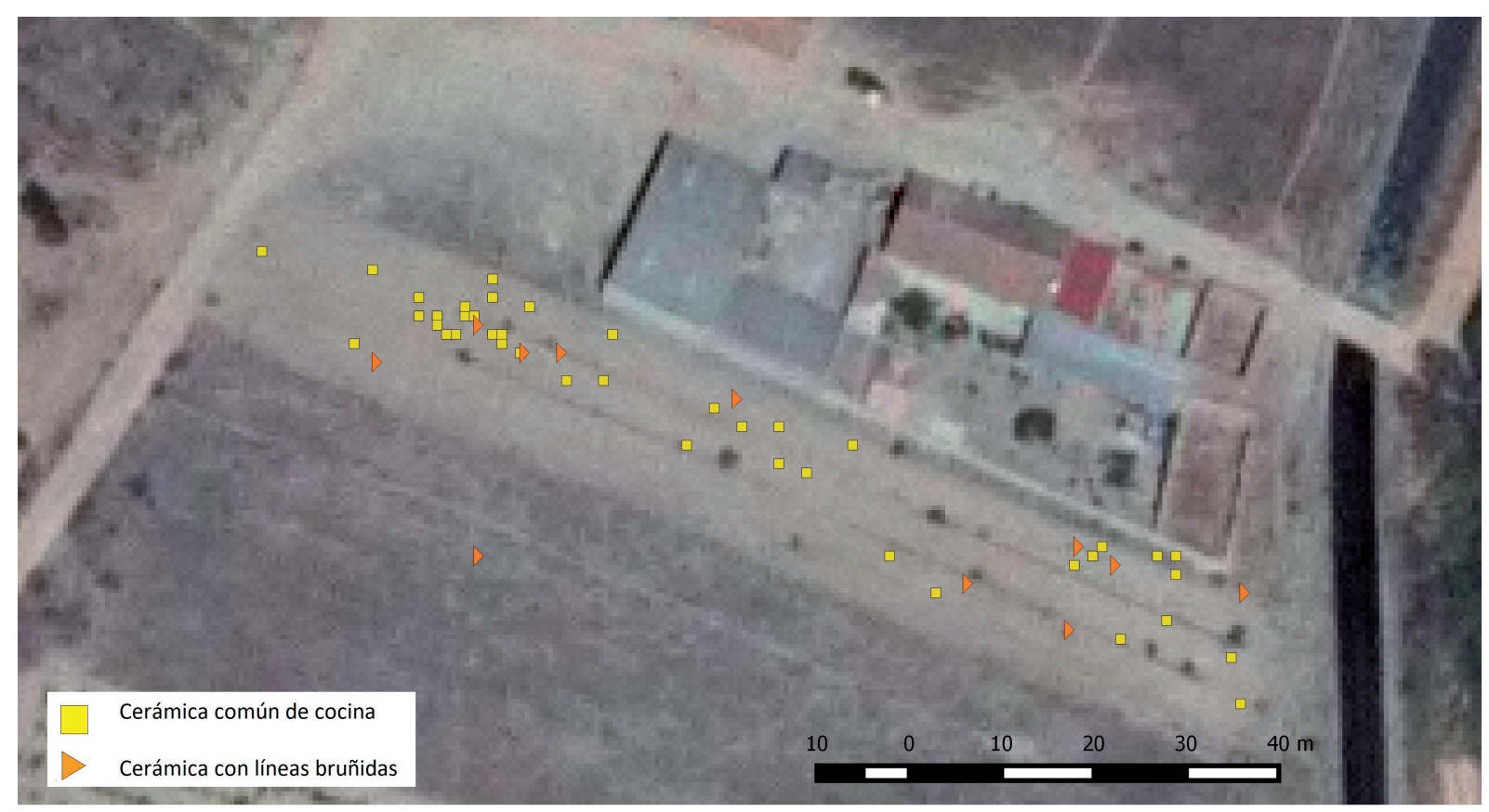

Figura 13: Tímulos (Toro). Dispersión de la cerámica común de cocina y de la cerámica común decorada con líneas bruñidas en el área prospectada. Base cartográfica del Instituto Geográfico Nacional (portal http://pnoa.ign.es/).

El Toro-Tejadillo y El Cementerio. Definir la composición social de las poblaciones que ocupan el espacio de la villa una vez que los indicadores aristocráticos desaparecen es un reto interpretativo. No puede descartarse, sin embargo, que pese al carácter humilde de la ocupación de la villa en el periodo suevo y visigodo, las aristocracias (nuevas o descendentes de las viejas familias romanas) continúen ejerciendo un cierto dominio sobre el espacio de la villa (Ariño 2013: 103-106, DiarteBlasco 2018: 62-67). Solo la villa romana de El Soldán, en el espacio agrario de Asturica, colapsa antes de alcanzar la secuencia bajoimperial, algo que en el caso de estudio se asocia a la dinámica de la explotación minera $\mathrm{y}$ sus peculiares formas de organización del espacio y de los patrones de asentamiento. Es probable, de hecho, que la más evidente reorganización del territorio asturicense se hubiese gestado a partir de mediados del siglo III, cuando muchas de sus minas estaban ya completamente abandonadas.

Por último, es especialmente relevante el caso de Brimeda, ya que plantea directamente el tema de la continuidad (o no) de la aldea medieval con respecto a espacios de hábitat preexistentes. Los resultados de la prospección parecen respaldar la información proporcionada por el documento del año 878 , en el que se presenta el origen de la aldea como un acto fundacional que incluye roturaciones, parcelación del espacio agrícola y construcción de espacios de vivienda. La prospección del territorio de Brimeda ha permitido recuperar materiales que pueden atribuirse a la secuencia visigoda, pero tan dispersos y en cantidad tan escasa que es difícil establecer con seguridad la existencia de un asentamiento humano previo al del siglo IX, si bien hay que tener en cuenta que la prospección no ha cubierto la totalidad del espacio en torno a Brimeda ni, por razones obvias, ha podido actuar sobre el solar de la villa. La recuperación de 50 fragmentos de cerámica común decorada con líneas bruñidas, fechada en el periodo plenomedieval, sería un refrendo de naturaleza arqueológica a la fuente documental que fecha el origen de la villa en el año 878. Este material está disperso en el espacio parcelado en torno a la villa, sin formar concentraciones que puedan interpretarse como puntos de hábitat. Suele considerarse que este material off-site es consecuencia del vertido de basura doméstica, al ser esta usada como abono y siendo la cerámica un aporte casual o secundario (Foley 1981, Wilkinson 1982 y 1989, Alcock et al. 1994).

A modo de conclusión puede decirse que los resultados de la investigación llevada a cabo nos sitúan ante una realidad distinta de la que había sido nuestra hipótesis de partida. Así, mientras que los centros 
urbanos no pueden subsistir sin un territorio dinámico que les suministre (gran) parte de los bienes que necesitan, los asentamientos rurales fechados entre c $400 \mathrm{y}$ c 800 , continúan desarrollando su actividad (y respondiendo a nuevas dinámicas) pese a que el núcleo del que fueron dependientes se encuentre en fase de abandono. Esta situación nos abre un nuevo horizonte de estudio en el que las preguntas se multiplican: ¿Hasta qué punto la relación entre ciudad y territorio fue tan estrecha y constante durante todo el Imperio Romano? ¿Es posible que esta se hubiese empezado a diluir a partir de los siglos IV y V y que algunos centros rurales hubiesen emprendido la vía hacia la autosuficiencia? Y, sobre todo, cuando en un determinado territorio una ciudad se abandona, ¿cuál o cuáles de los centros rurales tomaron el rol central (de control, de coerción, etc.) y de qué forma podemos identificarlo en el paisaje? Solo el análisis en profundidad de estas cuestiones y la implementación de los métodos y técnicas utilizados permitirá, esperemos que un plazo no demasiado dilatado, comprender cómo se desarticuló la organización rural romana y se gestó el inicio de una nueva organización del territorio que, junto a las ciudades, pueblos y aldeas, fueron fundamentales en la ordenación y jerarquización del incipiente paisaje medieval.

\section{Agradecimientos}

Este artículo ha sido escrito como parte del proyecto MED-FARWEST (University of Leicester, Reino Unido) financiado por el programa de investigación e innovación Horizon 2020 de la Unión Europea y, más concretamente, de un contrato Marie Sklodowska-Curie $\mathrm{n}^{\circ} 658045$. No obstante, los resultados han sido elaborados en el periodo de disfrute de un contrato Juan de la Cierva-Incorporación (MINECO, JCI-2015-24930), ya en la Universidad de Alcalá.

Estamos en deuda con el equipo del Museo de León, Luis Grau Lobo, Manuel Antonio García Garrido, Miryam Hernández Valverde y Ana Álvarez Martínez, por todas las facilidades que nos dieron para acceder a los fondos del museo, así como por la información que nos proporcionaron sobre aspectos que concernían a nuestra investigación. También queremos agradecer a Jesús Celis Sánchez, arqueólogo a cargo de la sección de Patrimonio Cultural en la Diputación de León, el que nos facilitara el acceso a los materiales arqueológicos de la villa romana de El Soldán. Agradecemos a Javier González-Tablas y Antonio Blanco el asesoramiento que nos han prestado en la catalogación de la cerámica prehistórica recuperada en el yacimiento de Tímulos. Estamos en deuda con Inés Centeno Cea por la información que nos proporcionó sobre la cerámica del periodo medieval en el valle del Duero, así como por compartir con nosotros sus opiniones personales sobre esta producción.

\section{BIBLIOGRAFÍA}

Alcock, S.E.; Cherry, J.F. y Davis, J.L. (1994): "Intensive Survey, agricultural practice and the classical landscape of Greece", en I. Morris (ed.), Classical Greece: Ancient Histories and Modern Archaeologies: 137-170. Cambridge, Cambridge University Press.

Andreu Pintado, J. (ed.) (2017): Oppida Labentia, transformaciones, cambios y alteración en las ciudades hispanas entre el siglo II y la tardoantigüedad. Serie Monografías "Los Bañales". Uncastillo, Fundación Uncastillo.

Arce, J. (2005): Bárbaros y romanos en Hispania (400507 A.D.). Madrid, Marcial Pons.

Ariño Gil, E. (2013): "El hábitat rural en la Península Ibérica entre finales del siglo IV y principios del VIII: un ensayo interpretativo". Antiquité Tardive 21: 93-123. <https://doi.org/10.1484/J. AT.5.101406>.

Ariño Gil, E.; Gurt i Esparraguera, J. M. y Palet i Martínez, J. M. (2004): El pasado presente. Arqueología de los paisajes en la Hispania romana. Salamanca, Barcelona, Ediciones Universidad de Salamanca, Ediciones Universidad de Barcelona.

Ariño Gil, E. y Dahí Elena, S. (2012): “La cerámica de los yacimientos rurales de la provincia de Salamanca (España) entre la Antigüedad Tardía y la alta Edad Media (350-700)". Archeologia Medievale 39: 371-383.

Ariño Gil, E. y Díaz, P. C. (2003): "Poblamiento y organización del espacio. La Tarraconense pirenaica en el siglo VI". Antiquité Tardive 11: 223-237 <https:// doi.org/10.1484/J.AT.2.300260>.

Ariño Gil, E. y Díaz, P. C. (2014): "La frontera suevovisigoda: ensayo de lectura de un territorio en disputa”, en R. Catalán, P. Fuentes y J.C. Sastre (eds.), Las fortificaciones en la Tardoantigüedad. Élites y articulación del territorio (siglos V-VIII d.C.): 179190. Madrid, La Ergástula.

Ariño Gil, E.; Didierjean, F.; Liz Guiral, J. y Sillières, P. (2007): “Albocela (Villalazán, Zamora). Interpretación de la ciudad romana a partir de la fotografía 
aérea y la prospección intensiva”, en M. Navarro Caballero y J. J. Palao Vicente (eds.), Villes et territoires dans le Bassin du Douro à l'époque romaine: Actes de la table-ronde internationale. Études 17: 171-193. Burdeos (2004), Burdeos, Ausonius Éditions.

Ariño Gil, E.; Riera i Mora, S. y Rodríguez Hernández, J. (2002): "De Roma al Medievo. Estructuras de hábitat y evolución del paisaje vegetal en el territorio de Salamanca". Zephyrus 55: 283-309.

Ariño Gil, E. y Rodríguez Hernández, J. (1997): “El poblamiento romano y visigodo en el territorio de Salamanca. Datos de una prospección intensiva". Zephyrus 50: 225-245.

Ariño Gil, E. y De Soto García, R. (2016): “Técnicas de muestreo en la prospección arqueológica: la experiencia del Ager Salmanticensis (Salamanca, España)". Anales de Arqueología Cordobesa 27: 35-58. < https://doi.org/10.21071/aac. v0i27.6288>.

Asensio esteban, J. Á.; Magallón Botaya, M. Á. y Sillières P. (2016): La ciudad romana de Labitolosa. El conjunto arqueológico de cerro Calvario (la Puebla de Castro, Huesca) en la Antigüedad y la Edad Media. Huesca, Instituto de Estudios Altoaragoneses.

Balado Pachón, A. y Martínez García, A. B. (2008): "Sobre el temprano asentamiento militar romano de El Teso de la Mora en Molacillos (Zamora) y la ubicación de la mansio de Vico Aquario". Boletín del Seminario de Arte y Arqueología 74: 149-195.

Bohígas Roldán, R. (1990): “El alfar medieval de 'Cuernos Pequeños', Alto de la Morterona (Saldaña, Palencia)", en M. A. Calleja González (coord.), II Congreso de Historia de Palencia Tomo 1, Prehistoria, arqueología e Historia Antigua: 221-241. Palencia, Diputación Provincial de Palencia, Departamento de Cultura.

Caballero Zoreda, L. (1974): La necrópolis tardorromana de Fuentespreadas (Zamora). Un asentamiento en el valle del Duero. Excavaciones Arqueológicas en España 80. Madrid, Ministerio de Educación y Ciencia.

Cabero Domínguez, M. C. (1995): Astorga y su territorio en la edad media (s. IX-XIV): evolución demográfica, económica, social, político-administrativa y cultural de la sociedad astorgana medieval. León, Universidad de León, Universidad de Oviedo.

Carro, J. (1934): En la enigmática Maragatería. Importantes descubrimientos arqueológicos. Madrid, Imprenta de Juan Pueyo.
Chavarría Arnau, A. (2007): El final de las villae en Hispania (siglos IV-VIII). Turnhout, Brepols.

Corcoran, S. (2003): "The donation and will of Vincent of Huesca: Latin text and English translation". Antiquité Tardive 11: 215-221. <https://doi.org/doi. org/10.1484/J.AT.2.300259>.

Dahí Elena, S. (2007): "Un contexto cerámico de la Antigüedad tardía: el yacimiento de San Pelayo (Aldealengua, Salamanca). Nuevos datos sobre la cronología de las pizarras visigodas". Pyrenae 38 (1): 57-77.

Dahí Elena, S. (2012): Contextos cerámicos de la Antigüedad Tardia y Alta Edad Media (siglos IV-VIII) en los asentamientos rurales de la Lusitania Septentrional (provincia de Salamanca, España). British Archaeological Reports, International Series 2401. Oxford, Archaeopress.

Diarte-Blasco, P. (2012): La configuración urbana de la Hispania tardoantigua. Transformaciones y pervivencias de los espacios públicos romanos (s. III$V I$ d. C.). British Archaeological Reports, International Series 2429. Oxford, Archaeopress.

Diarte-Blasco, P. (2018): Late Antique and Early Medieval Hispania: Landscapes without Strategy? Oxford, Oxbow Books.

Diarte-Blasco, P. y Gurt i Esparraguera, J.M. (2015): "La percepción del espacio en el urbanismo tardoantiguo: características evolutivas en el ejemplo hispano". Antiquité Tardive (Isidore de Séville et son temps) 23: 307-328<https://doi.org/10.1484/J. AT.5.109386>.

Domergue, C. (1986): "Dix-huit ans de recherche (1968-1986) sur les mines d'or romaines du nordouest de la Péninsule Ibérique", en Actas del I Congreso Internacional de Astorga Romana II: 7-101. Astorga (1986), Astorga, Ayuntamiento de Astorga.

Domergue, C. y Martin, T. (1977): Minas de oro romanas de la provincia de León. II, Huerña: excavaciones 1972-1973. Excavaciones Arqueológicas en España 94. Madrid, Servicio de publicaciones del Ministerio de Educación y Ciencia.

Fernández Ochoa, C.; Morillo Cerdán, Á. y López Quiroga, J. (2005): "La dinámica urbana de las ciudades de la fachada noratlántica y del cuadrante noroeste de 'Hispania' durante el bajo imperio y la antigüedad tardía (siglos III-VII d. C.)”, en J. M. Gurt i Esparraguera y A. Ribera i Lacomba (eds.), VI Reunió Cristiana Hispánica: les ciudats tardoantigues d'Hispania: cristianització i topografia: 95-120. Valencia (2003), Barcelona, Institut d'Estudis Catalans. 
Floriano Cumbreño, A. C. (1951): Diplomática española del periodo astur (718-910), II. Oviedo, Diputación Provincial de Oviedo, Instituto de Estudios Asturianos.

Foley, R. (1981): “Off-site archaeology: an alternative approach for the short-sited", en G. Isaac y N. Hammond (eds.), Pattern of the past: studies in the honour of David Clarke: 157-183. Cambridge, Cambridge University Press.

Fuentes Domínguez, Á. (1989): La necrópolis tardorromana de Albalate de las Nogueras (Cuenca) y el problema de las denominadas "necrópolis del Duero”. Serie Arqueológica Conquense. Cuenca, Diputación de Cuenca.

García-Entero, V. (2001): Los "balnea" de las "villae" hispanorromanas. Provincia Tarraconense. Monografías de Arquitectura Romana 5, Serie Termas 1. Madrid, Universidad Autónoma de Madrid.

García Marcos, V. y Burón, M. (2000): "Las termas menores de Asturica Augusta”, en C. Fernández Ochoa y V. García Entero (eds.), Termas romanas en el Occidente del Imperio: II Coloquio Internacional de Arqueología en Gijón: 207-214. Gijón (1999), Gijón Ayuntamiento de Gijón.

García Marcos, V. y Vidal Encinas, J. M. (1995): "Recent Archeological Research at Asturica Augusta". Proceedings of the British Academy 86: 371-394.

García Marcos, V. y Vidal Encinas, J. M. (1996): “Asturica Augusta: Recientes investigaciones sobre su implantación y desarrollo urbano”, en C. Fernández Ochoa (coord.), Los Finisterres Atlánticos en la Antigüedad. Época prerromana y romana. Coloquio Internacional, Homenaje a Manuel Fernández-Miranda: 135-145. Gijón (1995), Gijón, Ayuntamiento de Gijón.

García Rozas, M. R. (1995): “Arqueología romana en la provincia de Zamora", Historia de Zamora, Tomo. I. De los orígenes al final del Medievo: $267-$ 337. Zamora, Diputación de Zamora, Instituto de Estudios Zamoranos "Florián de Ocampo", Caja España.

González Serrano, C. (1990): “Avance de la excavación realizada en el Pago del Alba, Villalazán, Zamora", en Congreso de Historia de Zamora, Tomo II: Prehistoria, Mundo Antiguo: 497-513. Zamora, Diputación de Zamora, Instituto de Estudios Zamoranos "Florián de Ocampo".

Gorges J.-G. (1979): Les villas hispano-romaines. Inventaire et Problématique archéologiques. Publications du Centre Pierre Paris (E.R.A. 522), 4. París, De Boccard.
Gurt i Esparraguera, J. M. (2001): "Transformaciones en el tejido de las ciudades hispanas durante la Antigüedad Tardía: dinámicas urbanas". Zephyrus 5354: 443-471.

Gurt i Esparraguera, J. M. y Sánchez, I. (2011): “Episcopal Groups in Hispania". Oxford Journal of Archaeology 30 (3): 273-298. <https://doi.org/10.111 1/j.1468-0092.2011.00369.x>.

Kulikowski, M. (2005): “Cities and government in late antique Hispania: recent advances and future research", en K. Bowes y M. Kulikowski (eds.), Hispania in Late Antiquity: Current Perspectives: 3170. Leiden, Boston, Colonia, Brill.

Larrén Izquierdo, H. (1994): “Arqueología Preventiva y de Gestión. Zamora, Arqueología en Castilla y León 1991/1992". Numantia 5: 335-351.

Le Roux, P. (2009): “Cultos y religión en el Noroeste de la Península Ibérica en el Alto Imperio Romano: nuevas perspectivas". Veleia 26: 265-285.

López Rodríguez, J. R. (1985): Terra sigillata hispánica tardía decorada a molde de la Península Ibérica. Valladolid, Universidad de Valladolid, Junta de Castilla y León, Universidad de Salamanca.

Magallón Botaya, M. Á. y Sillères, P. (2013): Labitolosa (La Puebla de Castro, province de Huesca, Espagne). Une cité romaine de l'Hispanie citérieure. Mémoires 33. Burdeos, Ausonius Éditions.

Mañanes Pérez, T. (1977): "Materiales cerámicos de la villa romana de El Soldán, Santa Colomba de Somoza (León)". Sautuola II: 227-261.

Mañanes Pérez, T. (1982): Epigrafia y numismática de Astorga romana. Salamanca, Museo de los Caminos de Astorga, Ediciones Universidad de Salamanca.

Martín Arija, A. M.; Iglesias del Castillo, L.; Salvador Velasco, M. y Viñé Escartín, A. I. (1994a): "Nueva intervención arqueológica en el yacimiento El Alba, Villalazán (Zamora)". Anuario del Instituto de Estudios Zamoranos Florián de Ocampo 11: 19-41.

Martín Arija, A M.; Iglesias del Castillo, L.; Salvador Velasco, M. y Viñé Escartín, A. I. (1994b): "El Alba, (Villalazán): un importante yacimiento romano en la provincia de Zamora". Numantia 6: 61-79.

Martín-Bueno, M. (1999b): "La ciudad julio-claudia: ¿una estrella fugaz?", en R. de Balbín Behrmann y P. Bueno Ramírez (eds.), II Congreso de Arqueología Peninsular, Tomo IV, Arqueología Romana y Medieval: 117-122. Zamora (1996), Alcalá de Henares, Universidad de Alcalá, Fundación Rei Alfonso Henriques. 
Martín López, A. y Sevillano Fuertes, M. Á. (e.p.): “The role of Christianity in transforming the conventus of Asturica Augusta. New archaeological perspectives", en $V$ International Colloquium New Perspectives on Late Antiquity: The loss of Hispania. Ideology, power and conflict. Madrid (2016), e.p.

Martín Valls, R. (1973): "Hallazgos arqueológicos en la provincia de Zamora". Boletín del Seminario de Arte y Arqueología XXXIX: 403-414.

Martín Valls, R. (1995): "La Segunda Edad del Hierro", Historia de Zamora, Tomo I. De los orígenes al final del Medievo: 151-189. Zamora, Diputación de Zamora, Instituto de Estudios Zamoranos "Florián de Ocampo", Caja España.

Martín Valls, R. y Delibes de Castro, G. (1976): "Hallazgos arqueológicos en la provincia de Zamora (III)". Boletín del Seminario de Arte y Arqueología XLII: 411-440.

Martín Valls, R. y Delibes de Castro, G. (1977): “Hallazgos arqueológicos en la provincia de Zamora (IV)". Boletín del Seminario de Arte y Arqueología XLIII: 291-319.

Martín Viso, I. (2006): “Central places and territorial organization of communities: the occupation of hilltop sites in Northern Castile ( $6^{\text {th }}-11^{\text {th }}$ centuries)", en W. Davies; G. Halsall y A. Reynolds (eds.), People and Space in the Middle Ages, 300-1300: 167-185. Turnhout, Brepols.

Martínez Penín, R. (2007): "La producción cerámica medieval de Castrum Iudeorum (Puente Castro, León): análisis de los materiales de la campaña de 1999”. Arqueología y Territorio Medieval 14: 163 $207<$ https://doi.org/10.17561/aytm.v14i0.1508>.

Morillo Cerdán, Á. (1991): "Fortificaciones campamentales de época romana en España". Archivo Español de Arqueología 64: 135-190 <https://doi. org/10.3989/aespa.1991.v64>.

Morillo Cerdán, Á. y Amaré Tafalla, M. T. (2003): “Asturica Augusta como centro de producción y consumo cerámico", en P. García Díaz y C. Fernández Ochoa (coord.), Unidad y diversidad en el arco atlántico en época romana: 121-143. Oxford, Archaeopress.

Núñez Hernández, S. y Curchin, L. A. (2007): “Corpus des villes / Corpus de ciudades romanas en el valle del Duero", en M. Navarro Caballero y J. J Palao, Vicente (eds.), Villes et territoires dans le Bassin du Douro à l'époque romaine, Actes de la tableronde internationale. Études 17: 429-612. Burdeos (2004), Burdeos, Ausonius Éditions.

Orejas Saco del Valle, A. (1996): Estructura social y territorio. El impacto romano en la cuenca noroccidental del Duero. Anejos de Archivo Español de Arqueología XV. Madrid, Consejo Superior de Investigaciones Científicas.

Orejas Saco del Valle, A. y Morillo Cerdán, Á. (2013): "Asturica Augusta. Reflexiones sobre su estatuto y su papel territorial (finales del siglo I a.C. -principios del siglo III d.C.)", en R. M. Cid López y E. B. García Fernández (eds.), Debita verba: estudios en homenaje al profesor Julio Mangas Manjarrés, vol. 2: 93-119. Oviedo, Servicio de Publicaciones de la Universidad de Oviedo.

Palol, P. de (1958): "Las excavaciones de San Miguel del Arroyo. Un conjunto de necrópolis tardorromanos del valle del Duero". Boletín del Seminario de Estudios de Arte y Arqueología XXIV: 209-217.

Pascual Sánchez, M. (1991): “Aportaciones al estudio de la Historia de la población medieval de la provincia de Zamora", Primer Congreso de Historia de Zamora, Tomo 3. Medieval y Moderna: 183-202. Zamora, Instituto de Estudios Zamoranos "Florián de Ocampo", Diputación de Zamora.

Paz Peralta, J. Á. (1991): Cerámica de mesa romana de los siglos III al VI d.C. en la provincia de Zaragoza. (Terra sigillata hispánica tardía, African red slip ware, sigillata gálica tardía y Phocaean red slip ware). Zaragoza, Institución Fernando el Católico.

Paz Peralta, J. Á. (2008): "Las producciones de terra sigillata hispánica tardía," en D. Bernal y A. Ribera (eds.), Cerámicas hispanorromanas. Un estado de la cuestión: 497-539. Cádiz, Servicio de Publicaciones de la Universidad de Cádiz.

Paz Peralta, J. Á (2013): "La vajilla de cerámica hispánica tardía gris y naranja en Asturica Augusta (Astorga, León). Conjunto C". Ex Officina Hispana: cuadernos de la SECAH 1: 217-255.

Peñil Mínguez, J. (1987): "El Testar Medieval de Saldaña (Palencia): Camino de la Morterona", en Actas del II Congreso de Arqueología Medieval Española, vol. 3: 613-620. Madrid, Dirección General de Cultura.

Pérez Centeno, M. del R. (1990): "El poblamiento romano en Zamora durante el s. III d.C.", en Primer Congreso de Historia de Zamora, Tomo 2. Prehistoria e Historia Antigua: 445-454. Zamora, Instituto de Estudios Zamoranos "Florián de Ocampo", Diputación de Zamora.

Quirós Castillo, J. A. (2011): "Early medieval landscapes in north-wet Spain: local power and communities, fifth-centuries". Early Medieval Europe 19 (3): 285-311 <https://doi.org/10.111 1/j.1468-0254.2011.00321.x>. 
Quirós Castillo, J. A. (ed.) (2013): El poblamiento rural de época visigoda en Hispania. Arqueología del campesinado en el interior peninsular. Documentos de Arqueología Medieval 6. Bilbao, Universidad del País Vasco.

Rabanal Alonso, M. A. y García Martínez, S. M. (2001): Epigrafía romana de la provincia de León: revisión y actualización. León, Universidad de León.

Sánchez Badiola, J. J. (2004): El territorio de León en la Edad Media: poblamiento, organización del espacio y estructura social (siglos IX-XIII). León, Universidad de León.

Sánchez-Palencia, F. J. (1995): “Minería y metalurgia de la región astur en la Antigüedad" en Astures. Pueblos y culturas en la frontera del Imperio Romano. Catálogo de la Exposición: 141-157. Gijón, Gran Enciclopedia Asturiana, Ayuntamiento de Gijón

Sánchez-Palencia, F J.; Orejas, A.; Sastre, I. y Ruíz del Árbol, M. (2000): "Minería y organización del territorio en Hispania romana. Las zonas mineras de $\mathrm{As}$ turia Augustana", en Primer Simposio sobre la Minería y la Metalurgia Antigua en el SW Europeo, Serós 2000: 247-262. Serós, Centre d'Arqueologia d'Avinganya.

Sastre, I.; Orejas, A.; Currás, B. y Zubiaurre, E. (2017): "La formación de la sociedad provincial del Noroeste hispano y su evolución: civitates y mundo rural”. Gerión 35(2): 537-552<https://doi.org/http:// dx.doi.org/10.5209/GERI.59923>.

Sastre Blanco, J. C.; Catalán Ramos, R.; Fuentes Melgar, P.; Vázquez Fadón, M.; Rodríguez Monterrubio, Ó. y Álvarez Rodríguez, A. (2018): "Producciones cerámicas en el poblado de El Castillón entre los siglos V-VI d.C.”, en I. Marín Viso, P. Fuentes Melgar, J.C. Sastre Blanco y R. Catalán Ramos (coords.), Cerámicas altomedievales en Hispania y su entorno (siglos V-VIII d.C.): 379-400. Valladolid, Arbotante Patrimonio e Innovación S.L, Glyphos Publicaciones.

Sevillano Fuertes, M. Á. (2007): "La muralla romana de Astorga (León)", en A. Rodríguez e I. Rodà (coord.), Murallas de ciudades romanas en el occidente del Imperio: Lucus Augusti como paradigma, Actas Congreso Internacional: 345-357. Lugo (2005), Lugo, Diputación Provincial de Lugo.

Sevillano Fuertes, M. Á. (2013): “Un espacio público singular: la porticus del ara conventual o el foro de Asturica Augusta (Astorga, León)”, en B. Soler Huertas, P. Mateos Cruz, J.M. Noguera Celdrán y J. Ruiz de Arbulo Bayona (coords.), Las sedes de los "Ordines decurionum" en Hispania: análisis arquitectónico y modelo tipológico: 111-134. Anejos de Archivo Español de Arqueología 77. Mérida, Consejo Superior de Investigaciones Científicas.

Sevillano Fuertes, M. Á. y Vidal Encinas, J.M. (2000): "Las termas mayores de Astorga", en C. Fernández Ochoa y V. García Entero (eds.), Termas romanas en el Occidente del Imperio. II Coloquio Internacional de Arqueología en Gijón: 199-205. Gijón (1999), Gijón, Ayuntamiento de Gijón.

Sevillano Fuertes, M. Á. y Vidal Encinas, J.M. (2002): Urbs Magnifica. Una aproximación a la arqueología de Astúrica Augusta (Astorga, León). León, Museo Romano.

Teja Casuso, R. (1990): "La carta 67 de S. Cipriano a las comunidades cristianas de León-Astorga y Mérida: algunos problemas y soluciones", en A. González Blanco y J. M. Blázquez Martínez (eds.), Cristianismo y aculturación en tiempos del Imperio Romano, Antigüedad y Cristianismo VII: 115-124. Murcia, Universidad de Murcia.

Tomás Faci, G. y Martín Iglesias, J. C. (2017): “Cuatro documentos inéditos del monasterio visigodo de San Martín de Asán (522-586)". Mittellateinisches Jahrbuch 52: 261-286.

Vidal Encinas, J. M. y González Fernández, M. L. (2004): "La Legio X Gemina y Astúrica Augusta (Astorga, León)". Astorica 23: 35-63.

Vidal Encinas, J. M. y González Fernández, M. L. (2018): "Asturica Augusta: actualización de su urbanismo a la luz de las excavaciones recientes", en S. Martín Caballero, J. Santos Yanguas y L.J. Municio González (eds.), El urbanismo de las ciudades romanas del valle del Duero, Actas de la I Reunión de Ciudades Romanas del Valle del Duero: 273-298. Segovia (2016), Segovia, Junta de Castilla y León.

Vigil-Escalera Guirado, A. (2007): “Granjas y aldeas tardoantiguas y altomedievales de la Meseta. Configuración espacial, socioeconómica y política de un territorio rural al norte de Toledo (ss. V-X d. C.)". Archivo Español de Arqueología 80: 239-284 $<$ https://doi.org/10.3989/aespa.2007.v80>.

Vigil-Escalera Guirado, A. (2009): "Las aldeas altomedievales madrileñas y su proceso formativo", en J. A. Quirós Castillo (ed.), The Archaeology of Early Medieval Villages in Europe: 315-339. Bilbao, Universidad del País Vasco <https://doi.org/10.13140/ RG.2.1.4036.4000>.

Vigil-Escalera Guirado, A. (2013): "El registro arqueológico del campesinado del interior peninsular en época altomedieval", en J. A. Quirós Castillo (ed.): El poblamiento rural de época visigoda en 
Hispania. Arqueología del campesinado en el interior peninsular: 65-258. Documentos de Arqueología Medieval 6. Bilbao, Universidad del País Vasco.

Vigil-Escalera Guirado, A. (2015): Los primeros paisajes altomedievales en el interior de Hispania. Registros campesinos del siglo quinto d.C. Documentos de Arqueología Medieval 7. Bilbao, Universidad del País Vasco.

Villanueva Zubizarreta, O. (2011): “La ollería alcallería en la cuenca del Duero a lo largo de la Edad Media y Moderna", en J. Coll Conesa (coord.), Manual de Cerámica Medieval y Moderna: 87-115. Madrid, Museo Arqueológico Regional de la Comunidad de Madrid.
Whittaker, C.R. (1990): "The Consumer City revisited: the vicus and the City". Journal of Roman Archaeology 3: 110-118 <https://doi.org/10.1017/ S1047759400010862>.

Wilkinson, T.J. (1982): “The definition of ancient manured zones by means of extensive sherd-sampling techniques". Journal of Field Archaeology 9 (3): 323-333<https://doi.org/10.1179/0093469827915 $04616>$.

Wilkinson, T.J. (1989): "Extensive Sherd Scatters and Land-Use Intensity: Some Recent Results". Journal of Field Archaeology 16 (1): 31-46<https://doi. org/10.1179/jfa.1989.16.1.31>. 
